\title{
The Effects of Import Competition on Worker Health ${ }^{1}$
}

\author{
T. Clay McManus ${ }^{2}$ \\ University of Tennessee \\ Georg Schaur ${ }^{3}$ \\ University of Tennessee
}

\begin{abstract}
Occupational safety and health is an important determinant of workers' welfare. Our theory predicts that firms facing greater shut down risk reallocate resources to improve productivity at the expense of safety. Therefore, at firms facing the greatest shutdown risk due to import competition, safety conditions worsen following an import shock but firm productivity increases. We provide empirical evidence that the growth in Chinese imports in the years 19962007 significantly increased injury rates in the competing US manufacturing industries over the short to medium run, particularly at smaller establishments. Back of the envelope calculations show that the increase in injury risk at the smallest firms costs workers the equivalent of a 1 to 2 percent reduction in annual wages.
\end{abstract}

JEL: F16, F66, J81, J32, L60

Keywords: Import Competition, Safety, Injuries, Trade Liberalization

November 2014

\footnotetext{
${ }^{1}$ We would like to thank William S. Neilson, Marc-Andreas Muendler, Tibor Besedes, Tim Schmidt-Eisenlohr, Alexandre Skiba, Volodymyr Lugovsky, J. Scott Holladay, Scott Gilpatric, Matthew C. Harris, and John Bell for helpful comments, along with seminar participants at the University of Tennessee and the Midwest International Trade Meetings. We would also like to thank the Occupational Safety and Health Administration and the following researchers for making their data publicly available: Autor, Dorn and Hanson (2013), Pierce and Schott (2013), and Feenstra, Romalis, and Schott (2002).

${ }^{2}$ Department of Economics, University of Tennessee, Knoxville, TN 37919; email: tmcmanus@ vols.utk.edu

${ }^{3}$ Department of Economics, University of Tennessee, Knoxville, TN 37919; email; gschaur@utk.edu
} 


\section{Introduction}

Health and injury outcomes are important to workers and firms. Estimates reveal that in 2007 US firms and workers saw 9M occupational injuries and illnesses, 60,000 of which were fatal, that resulted in about 250B in costs to workers, firms and taxpayers (Leigh, 2011). Injury rates at US manufacturers are among the highest of any industry. ${ }^{4}$ These same firms and workers also continue to see significant import competition from low cost markets, China in particular, which has important wage and employment effects. Labor standards, health and safety conditions are an important part of the employment contract, but have not been examined in the face of trade liberalizations or import competition. In this paper we ask if import competition from foreign markets affects injuries and worker health in US firms.

The link between import competition and worker injuries is natural and supported by the intersection of evidence from the respective literatures. Import competition impacts firm survival (Pierce and Schott, 2013; Bloom et al., 2012, Bernard et al., 2006), labor markets (Autor et al., 2013), and firm investments in new technology (Ederington and McCalman, 2009). Literature on Occupational Safety and Health (OSH) shows that injuries are determined by the relative priority the firm places on safety aside other goals like output (Zohar, 2000, 2002), technology upgrading and investments, and labor market conditions (Probst and Brubaker, 2001). Together, the literature suggests that foreign competition will impact occupational injuries and worker welfare by affecting the firms' incentives related to output and safety. Welfare evaluations based on wages alone miss this effect of trade on workers' welfare.

We combine establishment-level panel data on injuries and illnesses at US firms from the Occupational Safety and Health Administration (OSHA) with two measures of Chinese import

\footnotetext{
${ }^{4}$ There were 4.6 injury and illness cases per 100 workers in manufacturing in 2012, compared to 3.8 in natural resources and mining and 3.7 in construction. (Bureau of Labor Statistics)
} 
competition, adapted from recent work by from Autor et al. (2013) and Pierce and Schott (2013) to study the link between import competition and worker health outcomes. Specifically, we apply differencing, fixed-effect and instrumental variable strategies to identify the causal effect of trade liberalization and supply-driven import shocks on injury and illness rates at competing domestic firms.

The estimates show that import competition has significant consequences for injuries in the short to medium run that are heterogeneous across firms in affected industries. Import competition raises injury rates at smaller establishments but the effect is insignificant and sometimes positive for the largest establishments in the industry. In our sample, the mean 5-year growth in Chinese imports across industries was about 128 percent. This increase in import exposure raised injury rate growth by about 13 percentage points at the smallest decile of plants and about 10 percentage points at the median. Using an alternative model grounded in trade policy, we estimate that the US permanently reducing tariffs on Chinese imports in 2001 increased injury rate growth over the next five years by an average of 6 percentage points at plants in the smallest decile.

Back-of-the-envelope calculations using these estimates show that Chinese import shocks increased annual injury rates at US manufacturers by 0.51 cases per 100 workers on average, and by 1.02 at the smallest plants. Estimates from the value of statistical life and injury literature shows that these increases in injury risk are important in magnitude and are equivalent to wage decreases of approximately $0.4-1.0$ percent and $0.8-2.0$ percent, respectively. ${ }^{5}$ For comparison, Arkolakis et al (2012) discuss gains in real income due to trade liberalization of 1.4 percent. If variable trade costs are eliminated, Melitz and Redding (forthcoming) find a welfare

\footnotetext{
${ }^{5}$ Estimates for the value of injuries vary across studies but generally range from $75 \%$ to $200 \%$ of yearly income. See Viscusi (1993) for a survey, and Hersch (1998) and Leeth and Ruser (2003) for later work.
} 
effect of 17 percent. In total, we estimate that supply-driven growth in Chinese imports was responsible for between 62,000 and 90,000 injuries and illnesses annually during 2001-2007, about 7 percent of all cases in manufacturing, and the total loss to worker welfare was between $\$ 2.2$ and $\$ 9$ billion each year. With this in mind, the effects of import competition on injuries are an important channel to consider for welfare overall and among workers at small establishments in particular.

Differencing and fixed effect strategies mitigate the effect of unobserved establishment, industry and geography specific characteristics. In addition, we tackle three identification problems that are important in determining the effects of import competition on worker injuries. First, we consider long and short time differences to distinguish between short and long run effect of import competition and injuries. Second, underreporting of injuries is a notorious problem in self-reported injury data; workers hide or work through injuries rather than report them due to fear of being fired later on (Boone et al., 2011; Boone and van Ours, 2006). As a robustness check we estimate the model separately on the rates of injuries by severity and therefore susceptibility to misreporting, and we discuss literature and incentives that mitigate the issue of misreporting. Third, it is difficult to capture the causal effects of the trade shock on domestic establishments, due in large part to the endogeneity of observed market outcomes (i.e. quantity of imports correlated with demand shocks), and so we adapt two different measures of import competition based on the alternative identification strategies in recent empirical work by $\mathrm{ADH}$ and PS that rely on considerably different identifying assumptions and each offer relative advantages in other regards.

Our theory motivates why we would expect that import competition raises injuries at small firms in the short run. The intuition is straightforward. At the firm, managers can increase 
workers' productivity by increasing the risk of injury. When making these decisions, firms consider the long term costs and the reputation effects of additional injuries. Because firms are judgment proof and future costs like demand penalties and productivity losses only matter if the firm is operational, the expected long run costs of injuries today are decreasing in the probability of the firm shutting down. Therefore, because import competition lowers the probability of firm survival, especially for less productive firms in the market, marginal firms respond by raising productivity at the cost of more injuries, extending the firm's life. This result is important in considering the short term effects of import competition and adjustment processes at firms that are most affected following a trade shock. In existing models these firms simply drop out and so these effects are not captured in comparisons of steady-state equilibria (e.g. Melitz, 2003).

Bloom et al. (2012) finds that the growth in Chinese imports in Europe significantly increased the average total factor productivity in competing domestic industries as a result of both low productivity-firm exit and improvements within surviving firms. The sources of observed intra-firm productivity gains are difficult to identify. They find that firms invest more in technology and R\&D, while other studies have presented different explanations that include, in support of our theoretical approach, manager adjustments to improve factor productivity and increase firm survival (Bloom and van Reenen, 2007). Also consistent with our intuition, Lazear et al. (2013) finds evidence that worker effort drives productivity increases: they find that the firm's realized productivity gains during a recession are the result of "making do with less", getting more effort from fewer workers. ${ }^{6}$

\footnotetext{
${ }^{6}$ Their model differs from ours in that the adjustment in their model is driven by workers who exert more effort to reduce the probability of job loss when unemployment increases as job loss is more costly. To the extent that import competition similarly deteriorates the value of being currently unemployed for a manufacturing worker - who might remain unemployed for longer or be forced to switch to a lower-wage occupation (as found in Ebenstein et al., 2014) - workers may increase their effort and be willing to accept worse safety outcomes following import competition.
} 
If we agree to suppose risk and injuries at work as part of the wage and compensation contract, then the predicted long-run labor market effects of trade in existing models provide useful insight for considering how import competition may affect occupational health. In standard trade models with heterogeneous firms and intraindustry trade, including Melitz (2003), bilateral trade liberalizations or productivity gains unambiguously increase real wages and improve welfare. The effects of unilateral liberalizations or asymmetric productivity gains, however, are less clear: Demidova (2008) shows productivity gains abroad hurt real wages (welfare) at home, while Demidova and Rodriguez-Clare (2013) finds the opposite in a model of balanced trade. Models with labor market frictions explain heterogeneous consequences across firms, even for identical workers. Egger and Kreickemeier (2009) and Amiti and Davis (2011) consider fair wage mechanisms where firms share rents with their workers to keep them from shirking on the job, and Helpman et al (2014) consider a labor market with search frictions where firms and workers bargain over the rents of a successful match. Supposing firms share rents partly in the form of better health outcomes, trade liberalization will improve working conditions at large firms where profits rise and deteriorate conditions at smaller firms that are not exporting and face more competition on the domestic market. We take away two conclusions from this literature for our empirical exercise. First, based on existing theories the overall effect of import competition on injuries is ambiguous. Second, the effect of import competition on injuries is heterogeneous across firms: if rents fall at low-productivity firms in particular as a result of import competition, then we expect that this leads to a deterioration of safety standards at small firms, theoretically the least productive (Melitz, 2003).

Our empirical exercise is most closely related to recent work by Autor et al. (2013) and Pierce and Schott (2013), which both study the consequences of product market competition on 
labor market outcomes. Autor et al. (2013) define labor markets geographically and find that growth in import exposure in a region increased unemployment rates, reduced labor force participation rates and reduced average weekly wages. Pierce and Schott (2013) exploit crossindustry variation in the effects of a 2001 change in US tariff policy towards China and find the policy significantly increased imports and reduced employment in US manufacturing industries. Our finding that greater import competition leads to higher injury rates at competing establishments supplements their results on adverse wage and employment effects.

We also contribute to literature on the interrelation between international trade and labor standards (see Brown, Deardorff and Stern, 1996; Brown, 2007) and in particular the subset of that work that focusses on how trade exposure affects labor standards in a competitive market. Most studies focus on the developing world and consider how wage gains from trade beget greater demand for standards - regarded as normal goods - in the long run. ${ }^{7}$ (child labor: Brown, Deardorf and Stern, 2002; Edmonds and Pavcnik, 2006). Our study contributes to this literature evidence of changes in safety outcomes in the short- to medium-run in a developed nation with well-defined institutions and relatively high standards ex-ante. Our empirical evidence of adverse safety effects, combined with outside evidence that manufacturing wages were not significantly affected (Autor et al., 2013), points to other channels through which trade affects standards outcomes in the labor market beyond the demand-side effects traditionally studied. As one explanation, our theory shows that import exposure in the goods market affects the amount of safety supplied by competing domestic firms following the shock by altering their expected survival.

\footnotetext{
${ }^{7}$ In addition to income growth, long-run improvements in OSH can also be attributable to an increase in the relative price of labor and technological progress, both in production technology that alters workers exposure to risk and in safety technology. (Ruser and Butler, 2009) Trade exposure may accordingly affect standards also through technology diffusion/spillovers from exporters and changes in factor prices, but neither channel seems a strong explanation of the effects among US workers studied here.
} 
The remainder of the paper is organized as follows: in Section 2 we develop a theoretical model relating injury rates to firm survival; we describe our empirical strategy, data, and measurement in Section 3; Section 4 presents our primary empirical results; we discuss the robustness of our findings and alternative explanations in Section 5; Section 6 concludes.

\section{Theoretical Model}

With their backs against the wall, firms facing import competition and struggling for survival increase productivity and prolong their existence, likely sacrificing their workers' health and safety in the process. Existing trade models tend to focus on comparing steady state equilibria before and after a change in openness to trade after the markets have readjusted and the least productive firms have dropped out. Our partial equilibrium theory provides intuition for what happens during the adjustment process at the most affected firms, many of which are not active in the new post-liberalization steady state. Therefore, we fill in intuition that is important in considering the effects of import competition on injuries, but is absent in existing general equilibrium models.

\subsection{Technology}

The firm relies on worker effort to produce output. The plant employs $L$ homogeneous workers and elicits from each an amount of effort $e$. We assume that the firm has constant returns to scale in total effort such that it has the production function $q=F(e, L)=\varphi e L$, where $\varphi$ parameterizes the firm's exogenous productivity.

It is costly for workers to exert effort, and so to elicit effort the firm must allocate resources to monitoring their output. For example, the manager at the firm might increase 
worker effort by spending his endowment of time monitoring worker output. Worker effort as a function of the wage paid and the amount of monitoring $m$ is given by $e(m)=w^{\alpha} m^{\beta}$, where $0<a, \beta<1$ such that effort is increasing and concave in both the wage and the level of monitoring. The cost of monitoring is developed below.

\subsection{Accidents and Injury Costs}

As a consequence of their job, workers at the firm face a risk of occupational injury or illness each period. These injuries are costly to the firm. In practice, firms pay substantial direct costs for injuries and illnesses that include workers' compensation pay, medical expenses, fines, and legal fees associated with processing and settling claims. For firms with experience-rated workers compensation insurance, high injury rates increase the cost of future coverage. Firms further incur equally substantial indirect costs resulting from workplace accidents that are not covered by insurance and include: disruptions in production, damage to capital, hiring and training costs for replacement workers, demand penalties from bad publicity, and diminished productivity resulting from employing a debilitated worker or a less-capable replacement and from lower employee morale. ${ }^{8}$ Behaviorally, injuries and illnesses bring disutility to a benign decision maker with other-regarding concerns for worker health.

To simplify the discussion, we henceforth use the term injury to broadly describe stochastic, work-related events which negatively affect worker health. We model injury costs in reduced form with the assumption that - consistent with many of the costs mentioned in the discussion above - the firm incurs some costs in the future as a result of injuries today. As in

\footnotetext{
${ }^{8}$ In the fair-wage literature, worker effort depends on how they are treated by the firm in the form of the wages they are paid. Analogously, worker effort might depend on how they are treated by the firm with regards to the workplace environment and safety.
} 
Melitz (2003), we assume that in each period there is an exogenous probability $\delta$ that the firm is forced to shut down. The expected total cost of an injury today is given by

$$
\mathrm{E}[C]=\int_{t=0}^{\infty}(1-\delta)^{t} e^{-r t} c(t) d t
$$

where $c(t)$ is the cost incurred $t$ periods after an injury and the interest rate $r$ is used as the firm's discount rate. We assume that injury costs depreciate over time at a rate of $d$ such that $c(t)=c d^{t}$. It follows that, in expectation, the total cost over the firm's lifetime of an accident today is given by: ${ }^{9}$

$$
\mathrm{E}[C]=\frac{c}{(\delta+r) d}
$$

Importantly, the cost of injuries is such that the firm is in effect "judgment proof": the costs are only incurred in future periods if the firm is still operating and therefore the expected lifetime costs to the firm of worker accidents is decreasing in the probability of the firm shutting down.

The specification that consequences of worker injuries are limited to the firm's survival is consistent with: financial liability for direct costs is limited for a corporation's decision makers following a shutdown; indirect costs such as diminished worker productivity, higher workers compensation insurance premiums, and demand penalties are all inconsequential if the firm shuts down; behaviorally, the manager's concern for workers well-being extends only so far as his tenure with the firm.

We simplify the model by assuming that wages are unaffected by injury risk in the short run, either because workers have asymmetric information and do not observe changes in risk or

\footnotetext{
${ }^{9}$ This is derived in the following manner: Let $C_{t}$ be the cost of an injury as of time $t$ for all future time periods. For periods of duration $\tau, C_{t}=\tau c+(1-r \tau)(1-\delta \tau) C_{t+1}$. For $C_{t+1}=d C_{t}$, we have $C_{t}=\frac{\tau c}{1-(1-r \tau)(1-\delta \tau) d}$. Taking the limit as $\tau \rightarrow 0$ yields $C_{t}=\frac{c}{(\delta+r) d}$ by L'Hopital's Rule.
} 
because they are just paid their compensating variation in the event of an injury and are therefore indifferent. We show in Appendix B that the model's predictions are consistent under an alternative specification that allows for compensating wage differentials .

\subsection{Safety Investments and Accident Rates}

In addition to monitoring effort, the firm chooses to expend an amount $s$ of its resources $T$ (e.g. manager's time) to improve workplace safety and lower the probability of injury. We assume that the probability a worker is injured is given by $P(s)=\left(1-\frac{s}{T}\right)^{\gamma}$ for $s \in[0, T]$, where $\gamma \geq 1$ such that the returns to safety - lower injury rates - are non-increasing. For simplicity, we assume that the firm is constrained in their endowed resources and that this constraint binds: $m+s=T$; resources spent monitoring effort are implicitly resources not spent improving safety. The probability distribution of worker injury as a function of effort monitoring is therefore

$$
P(m)=\left(\frac{m}{T}\right)^{\gamma}
$$

for $m \in[0, T]$, where $P_{m}>0$ and $P_{m m}>0 .{ }^{10}$ We normalize $T=1$, so $m$ can be thought of as the share of resources the firm allocates to improving safety.

We assume that likelihood of a particular worker getting injured is independent of the number of workers at the plant. The expected total cost of injuries in a period is therefore given by:

$$
C L=m^{\gamma} \frac{c}{(\delta+r) d} L
$$

\footnotetext{
${ }^{10}$ The positive relationship between accident rates and productivity (through elicited effort) in our model arises endogenously based on the assumption that the firm is constrained in its resources and effectively decides to what degree to push output and to what degree to push effort. We prefer this to the alternative approach of modeling the number of accidents as a direct function of worker effort such that accidents are a byproduct of higher intensity effort, though such a relationship would yield predictions to those in our model.
} 


\subsection{Demand}

We suppose the monopolist operates in a simple economy where the representative agent has quasi-linear preferences over a homogeneous good $q_{0}$ produced in a competitive market and the monopolist's good $q_{M}$ :

$$
U=q_{0}+\frac{1}{\rho} q_{M}^{\rho}
$$

where $0<\rho<1$ parameterizes elasticity of substitution.

The competitive good is chosen as the numeraire and its price is normalized to one. We assume that the consumer's endowment is such that he consumes some positive amount of both goods and therefore the monopolist faces the inverse demand curve:

$$
p_{M}\left(q_{M}\right)=q_{M}^{-\frac{1}{\sigma}}
$$

where $\sigma=\frac{1}{1-\rho}>1$ is the constant elasticity of demand.

\subsection{Equilibrium Effort and Safety}

The firm's survival probability is taken as exogenous and therefore choices today affect the future only insofar as injuries today are costly in future periods. The injury cost function captures these dynamics and therefore the firm faces the static problem:

$$
\max _{m, L} \pi=\varphi^{\rho}\left(w^{\alpha} m^{\beta} L\right)^{\rho}-w L-m^{\gamma} \frac{c}{(\delta+r) d} L
$$

s.t. $\quad 0 \leq m \leq 1$.

The key features of the model are that the firm faces a trade-off between improving productivity and protecting workers against injuries, and the relative incentives of each depend on the firm's strength in the market as the expected cost of an injury is decreasing in the likelihood of the firm shutting down. 
We focus our analysis on worker health and therefore simplify the problem by treating wages as fixed and normalizing them to one. ${ }^{11}$ The optimal level of effort monitoring for the firm is given by the interior solution

$$
m^{*}=\left[\left(\frac{\beta}{\gamma-\beta}\right)\left(\frac{d(\delta+r)}{c}\right)\right]^{\frac{1}{\gamma}}
$$

if $\frac{c}{d(\delta+r)} \geq \frac{\beta}{\gamma-\beta}$, which we henceforth assume to be true. The equilibrium amount of effort exerted by employees at the firm and the probability of their being injured are therefore:

$$
\begin{gathered}
e\left(m^{*}\right)=\left[\left(\frac{\beta}{\gamma-\beta}\right)\left(\frac{d(\delta+r)}{c}\right)\right]^{\frac{\beta}{\gamma}} \\
P\left(m^{*}\right)=\left(\frac{\beta}{\gamma-\beta}\right)\left(\frac{d(\delta+r)}{c}\right)
\end{gathered}
$$

The optimal amount of labor employed by the firm is given by:

$$
L^{*}=\left[\rho \varphi^{\rho}\left(\frac{\beta}{\gamma-\beta}\right)^{\frac{\beta \rho}{\gamma}}\left(\frac{\gamma-\beta}{\gamma}\right)\left(\frac{d(\delta+r)}{c}\right)^{\frac{\beta \rho}{\gamma}}\right]^{\frac{1}{1-\rho}} .
$$

\subsection{The Injury Effects of Greater Shutdown Risk}

In this section, we use comparative static analysis to predict changes in the variables of interest in response to an increase in the firm's probability of shutting down $\delta$. We use the functional specifications and closed-form solutions introduced above to present our results, and show that the predictions hold for a more general model in Appendix A.

Proposition 1a: Firms monitor worker effort more when the probability of shutting down is greater;

\footnotetext{
${ }^{11}$ A few examples of considerable empirical support for wage stickiness are Blinder and Choi (1990), Campbell and Kamlani (1997), and recently by Barattieri et al. (2014).
} 
Proposition 1b: Firms elicit greater effort from workers when there is greater shutdown risk.

Proof: $\quad \frac{\partial m^{*}}{\partial \delta}=\left(\frac{1}{\gamma(\delta+r)}\right)\left[\left(\frac{\beta}{\gamma-\beta}\right)\left(\frac{d(\delta+r)}{c}\right)\right]^{\frac{1}{\gamma}}=\left(\frac{1}{\gamma(\delta+r)}\right) m^{*}>0$.

$$
\frac{\partial e\left(m^{*}\right)}{\partial \delta}=\left(\frac{\beta}{\gamma(\delta+r)}\right)\left[\left(\frac{\beta}{\gamma-\beta}\right)\left(\frac{d(\delta+r)}{c}\right)\right]^{\frac{\beta}{\gamma}}=\left(\frac{\beta}{\gamma(\delta+r)}\right) e\left(m^{*}\right)>0 .
$$

The firm's level of monitoring is increasing in the shutdown rate because it lowers the marginal cost of eliciting greater effort: the higher injury rates that accompany more monitoring are less costly because the firm's expected total losses from an accident are decreasing in its probability of shutting down. A fall in the relative cost induces the firm to expend more resources monitoring worker output and therefore workers exert greater effort on the job. Proposition 2: Injury rates are increasing in the probability of the firm shutting down.

Proof: $\quad \frac{\partial P\left(m^{*}\right)}{\partial \delta}=\left(\frac{\beta}{\gamma-\beta}\right)\left(\frac{d}{c}\right)=\left(\frac{1}{\delta+r}\right) P\left(m^{*}\right)>0$.

Investments to improve workplace safety are less valuable on the margin following an increase in the shutdown rate because it reduces the expected total cost of injuries. The firm responds by substituting resources away from safety and towards improving productivity, increasing injury rates and harming worker health in the process. ${ }^{12}$

Proposition 3: An exogenous increase in the probability of shutdown results in an increase in the productivity of labor.

Proof: $\quad M P_{L}=\frac{\partial q}{\partial L}=\varphi$ and therefore $\frac{\partial M P_{L}}{\partial \delta}=\frac{\varphi \partial e^{*}}{\partial \delta}$, which is shown to be positive in the prooffor Proposition 1a.

\footnotetext{
${ }^{12}$ The negative relationship between firm survival and accidents arises similarly in the alternative specification where firms sink an unrecoverable fixed cost in safety investments (e.g. safety training for workers) and benefit in the future from lower accident rates only if they are operating.
} 
The firm becomes more productive (i.e. competitive) in a given period due to a lower survival rate as it pushes workers harder at the expense of their health. ${ }^{13}$ In our model, labor used today unambiguously increases in response to lower survival rates. Greater competition in this short run environment - where wages are sticky and demand is fixed - only affects today's profits insofar as it decreases the firm's survival rate and therefore reduces the cost of effort. The resulting increase in effort demanded by the firm makes each unit of labor more productive.

\section{Empirical Strategy}

Our theory and existing literature provide intuition that import competition affects injury rates in US firms. There are three conclusions from the theory and existing literature that we take to the data.

First, even with competitive labor markets, the effect of import competition on overall workers' compensation is ambiguous if trade liberalization is asymmetric and depends on the specific set-up of the model. To the extent workers care about safety and are compensated in that dimension also, this implies that the effect of import competition on injuries is an empirical question.

Second, our theory provides intuition for why marginal firms - expecting to drop out in the long run - have an incentive to lower safety standards following an import shock. In light of the correspondence between safety and wages in the labor market contract, existing trade models such as those incorporating fair wages provide intuition for the long run consequences of import competition for safety.

\footnotetext{
${ }^{13}$ Our model's predictions explain the productivity increases found in empirical exercises as partly the result of greater worker effort, which here comes at the expense of safety. If effort is not modeled or observed as an input to production so output is instead specified as a function of labor only: $q=\varphi e F(L)$. The estimate for the firm's total factor productivity $\hat{A}$ in the production function $q=A F(L)$ depends on both the firm's randomly drawn productivity parameter $\varphi$ and by its endogenously determined level of worker productivity $e$.
} 
Third, our model and existing models predict that the effect of import competition on safety is heterogeneous across firms. In our model, firms that are most likely to exit as a result of an import shock cheat on safety standards because the long term consequences have diminished. In the long run, trade models with rent sharing explain that a liberalization affects workers at surviving firms based on its consequences for the firm's profits, such that firms with less rents to share as a result of greater import competition may compensate their workers with lower safety standards and vice versa.

The main ingredients to examine these predictions are measures of injuries at firms, measures of import competition, and, a strategy that separates those firms that are most affect by import competition and distinguishes long-term equilibrium from short-term adjustment effects.

\subsection{Establishment Injury, Illness and employment Data}

Our data on worker health at US manufacturing plants was collected by the Occupational Safety and Health Administration (OSHA) as part of the OSHA Data Initiative (ODI). Since 1996, OSHA and state-level regulators have collected data on the number of reported injuries and illnesses at a sample of manufacturing establishments. Each year, approximately 50,000 manufacturing plants are drawn from the universe of all private sector establishments ${ }^{14}$ with at least 40 employees and within participating states. We use data for 1996-2007 in our main sample, closing the data window at the start of the Great Recession in accordance with recent work (e.g. ADH and PS). Our panel consists of 473,014 establishment-year observations of injury data spanning 172,188 unique establishments. The sample covers about $53 \%$ of total manufacturing employment over this time period.

\footnotetext{
${ }^{14}$ Per the Quarterly Census of Employment and Wages, less than $0.1 \%$ of manufacturing establishments in the US are government-owned and employ less than $0.5 \%$ of all manufacturing workers.
} 
Each plant self-reports the total number of injury and illness cases recorded in the year, the number of cases that required time away from work or restricted work or transfer to other duties, and the plant's equivalent full time employment, imputed as the total hours worked by all employees in the year divided by a full time employment standard of 2000 (50 weeks at 40 hours per week). We use this information to construct our primary measure of worker safety at the plant, the OSHA-defined Total Case Rate (TCR). The variable $\mathrm{TCR}_{p}$ is the incident rate of injuries and illnesses per 100 full-time workers in a year at plant $p$ :

$$
\mathrm{TCR}_{\mathrm{p}}=\frac{\# \text { Injuries and Illnesses } \times 200,000}{\text { Total Employee Hours Worked }}
$$

TCR is calculated with an employment measure defined by hours rather than employees such that the TCR gives a measure of risk per unit of time worked. Reporting errors in both hours worked and recorded injuries contribute to potential mis-measurement of this variable in the data. We eliminate outliers from the sample with an imputed TCR greater than $60-$ about $0.5 \%$ of establishment-year observations - which is twice the largest average for any industry over this time and about 8 times the average across industries. ${ }^{15}$ The distribution of TCR in the data is shown in Figure 1.

This source also provides the remaining plant-level data for our main sample. We take the natural $\log$ of employment $L_{p}$ as our measure of the size of plant $p$, in lieu of available sales or output data. ${ }^{16}$ This is recorded as the average number of all workers across the pay periods in

\footnotetext{
${ }^{15}$ We also eliminate 8 observations with employment above 25000 as apparent reporting errors. None report employment above 10000 in any preceding or following year.

${ }^{16}$ As a robustness check, we also use an imputed measure that converts hours worked to the number of equivalent fulltime workers at the plant and find similar results/ Pierce and Schott (2013) report that their results are similar under either an hours-worked or employee headcount measure in related work on the employment effects of import competition.
} 
the year. The plant's primary industry $j$ is recorded each year at the SIC4 level. ${ }^{17,18}$ Summary statistics for injury and employment variables at the establishments in our sample are provided in Panel A of Table 1.

We compare our sample to industry data for the population of establishments to evaluate the representativeness of our establishment-level measures. For injury rates, the correlation coefficient between the industry-average TCRs for our sample and those for the full industry population reported by the Bureau of Labor Statistics (BLS) is $0.812^{19}$. Aggregate industry employment in our data is highly correlated with the population estimates reported in the NBERCES Manufacturing Industry Database and have a correlation coefficient of 0.823 at the fourdigit 1987 Standard Industrial Classification (SIC4) level. The distribution of establishments in our sample by employment size is shown in Table 2, where we also compare the distribution for our sample to that for the population of manufacturers reported in County Business Patterns data. While the data are highly detailed and allow for the identification of the effect of import competition on injuries, they do not come without problems. The size minimum for sampled establishments was originally 60 employees in 1996 and 50 in 1997, and changed to 40 thereafter. Further, selection is based on a BLS record of employment that may not equal the amount reported in our data as a result of changes in employment over the year and potential reporting errors. ${ }^{20}$ Lastly, all states participated in the ODI program at first but several self-

\footnotetext{
${ }^{17}$ A very small share of our sample $(<0.2 \%)$ do not report valid SIC4 codes. About half of those report a four-digit number but one that does not correspond to an accurate SIC4, including SIC4s xxx0. These plant-year observations are omitted from the sample.

${ }^{18}$ We include all industries in our main specifications, but find similar results in a robustness check where we follow Bernard et al. (2006) and others and estimate the model on a sample that excludes SIC codes ending in "9", which label industries with catch-all products "not elsewhere classified".

${ }^{19}$ In support of our excluding the outliers, this measure is 0.086 when TCRs greater than 60 are included.

${ }^{20}$ About $15 \%$ of observed plants have an imputed employment measure less than the year's sampling minimum. Most are just below the margin (likely symptomatic of a true disparity between recorded employment and imputed employment as fulltime equivalent of hours worked), but about $4 \%$ are less than half of the minimum (potentially due to inaccurate self-reporting).
} 
regulated states discontinued participation during our panel: OR, WA, and WY in 1997, SC in 1999, and AK and AZ in 2006. We estimate our main specification using all eligible observations in the sample, but we run several robustness checks with respect to sample selection issues. First, we estimate the model on a sample that excludes plants with imputed employment below the minimum for the year to account for potential misreporting. We then further restrict the sample to exclude observations in all years with an employment measure of less than 60 FTE to address dynamic selection concerns associated with the changes in eligibility. The first cut eliminates $14 \%$ of plant-year observations - representing $2 \%$ of employment - from the sample. The second cut eliminates an additional $16 \%$ of plant year observations and $4 \%$ of employment. Next, we drop all states that discontinued participation in the ODI program at any point during our data window to account for potential endogeneity due to non-random attrition at the state level, which account for about $2 \%$ each of total plant-year observations and employment in the full sample. Our overall conclusions remain the same for each robustness check.

Establishments that change SIC4-level industries across an interval of time are excluded from the sample for our difference specifications because the switch creates a spurious change in the industry-level measure of import competition and also likely affects injury rates via changes in production processes and technology. For our estimating samples of changes over $d=[1,6]$ years, this excludes $2.5 \%, 5.1 \%, 6.5 \%, 7.3 \%, 8.3 \%$ and $9.3 \%$ of observations, respectively.

\subsection{Import Competition: Chinese Supply Shocks}

We work with two measures of import competition in an industry. Our first measure is the percentage growth in imports in the US from China in industry $j$ over an interval of $d$ years, $\Delta \ln \left(M_{u c, j}\right)^{t: t+d}$. It is compiled by Autor et al. (2013) in their study of employment and other 
labor market effects of import competition and described in more detail there. ${ }^{21}$ Briefly, they concord data from the UN Comtrade Database for imports of Chinese products to the manufacturing industries that produce the (competing) products, making use of the crosswalk in Pierce and Schott (2012). They slightly aggregate SIC4 industries so that each is matched to at least one product code, such that real value of imports each year is allocated across 397 manufacturing industries defined at the SIC4 level.

Realized import growth is presumably correlated with industry demand shocks, which may have competing effects on firm outcomes and bias the estimated effects of import growth towards zero. In response, Autor et al. instrument for Chinese imports in the US with Chinese imports in a set of other OECD countries ${ }^{22}$ to identify supply-driven import shocks, and estimate the model using two-stage least squares (2SLS). We apply the same identification strategy out of concern that injury rates are similarly correlated with demand shocks, which would bias our results. $^{23}$ The main identifying assumption for the IV is that the correlation in Chinese export growth to the US and to other OECD countries over a period is driven by changes in trade costs and China's productivity.

Autor et al. identify three threats to this assumption that are also relevant for our analysis. One concern is that product demand shocks may be correlated across the US and other highincome countries, and therefore the first-stage IV results are not capturing the supply-side effect only. To check this, they apply a gravity strategy that isolates the import growth attributable to changes in trade costs and China's productivity. They find similar results across the

\footnotetext{
${ }^{21}$ This bilateral industry-level trade data is publicly provided on David Dorn's website, for which we are grateful.

${ }^{22}$ They are Australia, Denmark, Finland, Germany, Japan, New Zealand, Spain, and Switzerland.

${ }^{23}$ The direction of the bias is theoretically unclear. Our theory predicts that a demand shock will improve injury rates if it increases the firm's survival rate, while some OSH literature argues that demand shocks hurt workers as firm's push workers harder, hire inexperienced labor to meet greater demand, or use dated or unsafe surplus equipment.
} 
specifications and therefore conclude that correlated demand shocks are not driving their estimates for employment and wage effects. We proceed with the same assumption for our identification of injury effects. Second, the correlation may be driven by adverse productivity shocks to US producers that are being supplanted by Chinese imports in US and other OECD markets, but China's explosive productivity growth - about $8 \%$ over this period (Brandt et al., 2012), more than double that in the US - make it the more likely driver of its export growth across the markets. Lastly, common technology shocks across the US and other high-income countries that adversely affect labor-intensive industries may drive up Chinese imports.

However, Chinese export growth to the US greatly outpaced that of other low and middleincome nations which may similarly exploit an adverse shock, suggesting that the growth was driven by positive productivity shocks in China and falling trade costs for Chinese imports over this period.

\subsection{Import Competition: Permanent Tariff Reductions}

Our second measure of import competition is adapted from Pierce and Schott (2013) and links establishment-level injury rates to a change in US trade policy towards Chinese imports. The US granted China Permanent Normal Trade Relations (PNTR) in 2001 when it acceded to the WTO. ${ }^{24}$ Previously, US Congress voted each year to grant China the lower NTR tariff rates temporarily, and the votes were often heavily contested. ${ }^{25}$ Permanently reducing tariff rates for Chinese imports eliminated uncertainty over future trade costs and encouraged Chinese firms to incur the fixed cost to export to the US, even though the applied tariff rates were unchanged. Handley and Limão (2013) find that the reduction in tariff uncertainty explains 22-30\% of

\footnotetext{
${ }^{24}$ The vote took place in October 2001, and the change became effective when China joined the WTO in 2001. Following Pierce and Schott, we use 2001 as the year of the shock.

${ }^{25}$ The House of Representatives voted against temporary NTR status for China in 1990, 1991 and 1992, following the Tiananmen Square incident, but the Senate failed to act on those votes and the status was granted in each year.
} 
Chinese exports following its accession to the WTO. The ensuing import growth is especially large for products where the tariff differential is large. Considerable heterogeneity in productlevel tariff rates provides cross-industry identifying variation in the effects of the liberalization that we take to our data.

To quantify the shock in an industry, Pierce and Schott (2013) define the "NTR gap" as the difference between the NTR tariff rate and the non-NTR (Column 2) tariff rate for a product, and concord these to industries based on the products they produce. We construct our measure similarly, using tariff data from Feensta et al. (2002) and the matching procedure from Pierce and Schott (2012) to assign products to industries at the SIC4 level. ${ }^{26,27}$ The industry NTR gap is defined as the average across all goods produced. The mean NTR gap for establishments in our sample is about 0.31 and the standard deviation is 0.16 .

Our empirical analysis identifies the effects of PNTR on injury rate growth at establishments in competing industries. This measure of import competition relies on altogether different exogeneity assumptions than our first, though the identification concerns are similar: changes in injury rates may be correlated with demand shocks and with productivity shocks at US firms that are unrelated to Chinese import competition. Our estimates would be biased if these factors also affected the NTR gap. For example, if the US changed tariff rates near 2001 to protect industries suffering demand slumps that also affected injury rates, this would drive a relationship across industries between the NTR gap and injury rates before and after PNTR that is unrelated to import competition. However, there were few changes to tariff rates, and none to

\footnotetext{
${ }^{26}$ Specifically, three steps are taken to match HTS8 tariffs to SIC4 industries. The first step is a straight match using the concordance from the Bureau of Economic Analysis, which matches $63 \%$ of products. Next, we concord an HTS8 product to a SIC4 if all other products in its seven-digit "family" match to the same SIC4. We repeat the process using six-digit families and so forth, and this matches an additional $29 \%$ of products. Last, in the ordered set of HTS8 codes, we assign a product to a SIC4 if the industry preceding the gap is the same as the industry following the gap, which matches an additional $3 \%$ of products.

${ }^{27}$ We are grateful to Feenstra et al. (2002) for making the US tariff data publicly available through John Romalis' website and Pierce and Schott for making their concordances available through Peter Schott's website.
} 
non-NTR rates (which explain $89 \%$ of the variation in NTR gaps), in the decade leading up to PNTR, and therefore NTR gaps are plausibly exogenous to changes in injury rates leading up to 2001. Further, Pierce and Schott (2013) show that their results for employment growth are robust to using 1989 tariff rates to construct the NTR gap. We follow their main specification and define the measure using 1999 tariff rates.

\subsection{Comparing the Two Measures of Import Competition}

We test for the injury effects of import competition using two different measures, each offering relative advantages. The NTR gap is grounded in policy and allows us to directly identify how changes in tariff policy affect worker injuries. It does not capture the effects of import growth sourced from unrelated changes in China's competitiveness in the market - like productivity shocks due to greater access to foreign capital and intermediate inputs, technology spillovers, and export subsidies. The other measure, under the identifying assumptions above, captures the total import growth driven by all of these broad supply-side effects (including PNTR), though it does not disentangle them. As a result, we should expect the estimated effects of PNTR to be smaller than those for the import growth measure.

Comparisons across the two are imperfect, however, because of differences in the identification strategies. The import growth measure provides rich identifying variation both across industries and time, allows us to use a greater number of observations in our estimating sample. The NTR gap, on the other hand, is time invariant, and identification relies on a onetime policy change. This provides a cleaner platform for studying short-run versus medium/long-run responses to an import shock but reduces the number of observations used in the estimating sample. Identification is discussed in detail below. 


\subsection{Empirical Models}

Based on the identifying variation available in the two measures of import competition, we work with two empirical models. Let $p$ denote plants, $r$ geographic regions defined as US Census Commuting Zones (CZs), $j$ denote industries at the SIC4 level, and $t$ denote years. The first empirical model we consider relates the log change in injury rates over $d$-years to the contemporaneous log increase in supply-driven imports from China in the US that compete with the establishment's primary industry and an interaction of that term with establishment employment size in the base year $t$.

$$
\begin{aligned}
\text { (1) } \Delta \ln \left(T C R_{p j}\right)^{t: t+d}= & \alpha+\beta_{1} \Delta \ln \left(M_{u c, j}\right)^{t: t+d}+\beta_{2} \Delta \ln \left(M_{u c, j}\right)^{t: t+d} \times \ln \left(L_{p}^{t}\right)+ \\
& \gamma \ln \left(L_{p}^{t}\right)+\delta_{t}+\delta_{j}+\varepsilon_{p j r t}
\end{aligned}
$$

Described above, we use an instrumental variables strategy based on Autor et al (2013) to isolate the effects of import growth driven by Chinese productivity shocks and falling trade costs (and not demand shocks). With the interaction term, we have two endogenous variables, $\Delta \ln \left(M_{u c, j}\right)^{t: t+d}$ and $\Delta \ln \left(M_{u c, j}\right)^{t: t+d} \times \ln \left(L_{p}^{t}\right)$, and so we use the two instruments $\Delta \ln \left(M_{o c, j}\right)^{t: t+d}$ and $\Delta \ln \left(M_{o c, j}\right)^{t: t+d} \times \ln \left(L_{p}^{t}\right)$, where $M_{o c, j}$ is the amount of Chinese imports in industry $j$ in a set of other OECD countries. We estimate equation (1) using 2SLS with the two first stage regressions:

$$
\begin{aligned}
\text { (1a) } \Delta \ln \left(M_{u c, j}\right)^{t: t+d}= & \alpha+\beta_{1} \Delta \ln \left(M_{o c, j}\right)^{t: t+d}+\beta_{2} \Delta \ln \left(M_{o c, j}\right)^{t: t+d} \times \ln \left(L_{p}^{t}\right)+ \\
& \gamma \ln \left(L_{p}^{t}\right)+\delta_{t}+\delta_{j}+\varepsilon_{p j r t}
\end{aligned}
$$




$$
\begin{aligned}
\text { (1b) } \Delta \ln \left(M_{u c, j}\right)^{t: t+d} \times & \ln \left(L_{p}^{t}\right)=\alpha+\beta_{1} \Delta \ln \left(M_{o c, j}\right)^{t: t+d}+\beta_{2} \Delta \ln \left(M_{o c, j}\right)^{t: t+d} \times \ln \left(L_{p}^{t}\right)+ \\
& \gamma \ln \left(L_{p}^{t}\right)+\delta_{t}+\delta_{j}+\varepsilon_{p j r t}
\end{aligned}
$$

There was a structural decline in US worker injury rates over the period we study, 19962007, attributable in part to rising medical costs, an increase in demand for safety at work, greater regulation, safety technology improvements and production technology changes that reduced worker's exposure to risk. Some industries were more affected than others. The industry fixed effects control for the trend in injury rates for 1996-2007 (in $d$-year log growth), so that the coefficients $\beta_{1}$ and $\beta_{2}$ jointly identify the within-plant change explained by the Chinese import shock over $d$ years but not the long run trend. With this specification, we rely on variation in within-industry Chinese import shocks across time to identify the short to mediumrun effects of interest and disentangle these from long-run changes that are orthogonal to the short-term import shocks. Under the identifying assumptions above, our estimation will still capture the effects of adjustments that are endogenous to Chinese supply shocks during the period - e.g. trade-induced technology upgrading (Bloom et al. 2012).

We estimate equation (1) for $d=[1,6]$ to look at the effects of import shocks over the short run versus the medium to long run. There are some tradeoffs across the model specifications for shorter and longer intervals. We are left with the most observations when specifying the model in one- or two-year differences, but the instruments are weakened to the extent Chinese supply shocks are asynchronous across high income countries. On the other hand, the correlation import growth over a five- or six-year span is more forgiving of smaller delays in the shocks across markets but we are left with fewer observations, due to both the bounds of the panel and the increasing probability of a plant shutting down or switching 
industries over longer time horizons. As we increase $d$ in our fixed effects specification, we are left with increasingly less identifying variation in industry import shocks during 1996-2007 and so we estimate the model out to six-year differences only.

Our second model employs the policy experiment to identify the effects of permanent tariff reductions granted China in 2001 on worker injuries at competing US manufacturers. The specification is similar to that used by Pierce and Schott (2013) to study the employment effects of PNTR. We use a difference-in-difference (DiD) strategy to compare the within-plant change in injury rates across industries with higher and lower NTR gaps (first difference) before and after PNTR in 2001 (second difference). We estimate the following DiD equation for two base years, denoted by $t$, and differences over $d$ years:

$$
\text { (2) } \begin{aligned}
\Delta \ln \left(T C R_{p j}\right)^{t: t+d}= & \alpha+\beta_{1} \mathrm{NTRGap}_{\mathrm{j}} \times 1_{t \geq 2001}+\beta_{2} \mathrm{NTRGap}_{\mathrm{j}} \times 1_{t \geq 2001} \times \ln \left(L_{p}^{t}\right)+ \\
& \gamma \ln \left(L_{p}^{t}\right)+\delta_{t}+\delta_{j}+\varepsilon_{p j r t}
\end{aligned}
$$

Base-year fixed effects control for the common change in injury rates across industries in the post-PNTR period and industry fixed effects account for the common trend in industry injury rates that spans the pre- and post-PNTR periods.

One threat to identification arises because PNTR coincides with the business cycle peak in 2001, and the literature finds that reported injury rates are procyclical. Pierce and Schott deal with the issue in their main specifications by comparing changes post-2001 to the changes that followed the previous peak in 1990. Our data begins in 1996, however, and so we cannot follow suit. In light of this, we instead compare injury growth over the $d$-years immediately preceding and immediately following PNTR, so that we use the base years $t=\{2001-d, 2001\}$ and look at spells of $d=[1,5]$ years. 
We cannot entirely rule out that the industry-specific NTR gap is correlated with the industry-specific effects of the business cycle on worker injuries, but it seems unlikely that these potential confounds drive the results of our identification for three reasons. First, discussed above, the instrument is presumably exogenous to changes in the macroeconomy in 2001 - and specifically inter-industry heterogeneity in those changes - because NTR gaps do not change very much in the decade leading up to PNTR. Second, the literature suggests that reported injury rates are procyclical, in which case differences in the pre- and post-PNTR injury rates caused by changes in the macroeconomic environment would seem to bias against the result we find: injury rate changes pre-PNTR would be pushed upward by falling unemployment and increasing output while the opposite would be true in the recessionary period immediately following PNTR as the economy slumped and this put downward pressure on injury rates. Third, changes in the macroeconomy across the pre- and post-PNTR periods must account for heterogeneous effects across two dimensions to explain our results: between manufacturing industries in a manner correlated with their NTR gaps and within manufacturing industries in a manner correlated with plant size. We argue therefore that our difference-in-difference specification comparing changes on each side of 2001 yields consistent estimates of the injury effects of PNTR. The results are consistent in sign with those of our first measure of import competition, which isn't anchored about 2001.

There are several identification issues that are important. The first is measurement error in the dependent variable. If this measurement error is random, then measurement error in the dependent variable increases standard errors but does not bias the coefficient estimates. The concern is that measurement error is not random in our estimating equations. For example, it may be the case that workers at dying establishments are more like to report injuries. In that case, 
part of $\beta_{2}$ captures misreporting. It is not clear that this is true, however. Even at dying establishments, workers want to preserve a good reputation as they likely have to hunt for new jobs in the future. Nevertheless we will perform a robustness check using the rate of fatalities and more serious nonfatal injuries and illnesses only - those that required time away from work, restricted work or transfer - under the premise that these incidences cannot be as easily hidden and are less susceptible to strategic misreporting.

Next, the measure of import competition needs to be exogenous. Discussed above, our two measures of import competition deal with this problem differently. Identification with the import growth measure relies on an IV strategy that follows Autor et al. (2013): we instrument for import growth in the US using the corresponding growth in Chinese imports in a set of other developed economies, $M_{o c, j}$, and estimate the model using two-stage least squares (2SLS). Exogeneity in the NTR gap measure is grounded in the fact that NTR and non-NTR tariff rates were set long ago and there were few changes in the decade leading up to PNTR, suggesting the measure is not endogenous to market conditions near its implementation in 2001 that may also correlate with injury rates.

Finally, a key connection between our empirical specification and theory is the interaction of import competition with establishment size. The main identification assumption is that, in the short run, import competition increases the shutdown rate for smaller plants and has less of an adverse effect at larger plants (which may even see an improvement in their survival prospects). The literature links import competition to lower firm survival rates (Bernard et al. 2006a; Pierce and Schott, 2013) and finds heterogeneous effects such that shutdown rates increase the most at the least productive firms (Bernard et al. 2006b). We do not directly observe output or productivity in our establishment data and therefore use size, measured as 
number of employees, to proxy for productivity. The connection between productivity and labor, $L_{\varphi}>0$, is consistent with our theory and with standard trade models such as Melitz (2003), where the least productive firms are the smallest firms and drop out in the event of a trade liberalization.

\subsection{Predictions}

Our theory predicts that worker injury rates will worsen at a plant that faces an adverse shock to its survival rate. Based on the identifying assumption that import competition reduces survival rates at the smallest establishments, we predict that $\beta_{1}$ is positive. The sign of $\beta_{2}$ indicates how the marginal effect of imports differs at larger establishments relative smaller ones. Empirical evidence finds that import competition lowers survival rates most at the least productive firms and we assume that the less productive establishments are smaller, ceteris paribus. We therefore expect $\beta_{2}$ to be negative, indicating the effects of import competition on injuries are heterogeneous and diminishing in size.

For $\beta_{1}>0$ and $\beta_{2}<0$, under the necessary identification assumptions, we conclude that import competition tends to increase injuries at small establishments and less so at large ones, and tends to increase injuries at establishment sizes for which $\beta_{1}+\beta_{2} \ln (L)>0$. It is not clear based on the theory and literature whether injury rates improve at more productive firms, and so we are agnostic about the average effect of imports on injuries across all establishments, the sign of $\beta_{1}+\beta_{2} \ln (\bar{L})$. In addition to the within-plant changes we estimate empirically, import competition may affect average injury rates by inducing labor reallocations across plants. If workers move to safer plants when their employers' layoff or shutdown due to the import shock, this may lower average injury rates even if their new employer is relatively more risky than it was before the shock. Trade theory with heterogeneous firms (e.g. Melitz, 2003) explains that 
a liberalization drives labor to more productive firms in the long run as the mass of lowproductivity firms gradually exits the market, and so we might expect these adjustments to put downward pressure on average injury rates in the long run.

The theory gives no guidance to distinguish short term from long term effects. We address this problem empirically. The sample for each of our difference specifications includes only plants which are observed in the data at both ends of the time interval $t+d$.

Establishments that do not survive the duration of the period are excluded. Therefore, we expect that when we take longer time differences, the sample consists of relatively more establishments that ultimately survive and fewer marginal establishments on their way out. With short differences, we sample relatively more establishments that ultimately shutdown as a result of import competition. Therefore, the results for shorter differences are consistent with our theoretical model of short run behavior, but over longer differences the results are more consistent with existing models comparing two steady-state equilibria. We are limited by the data to looking at differences of up to five and six years only, but we evaluate the trends in our results across these intervals with respect to the predicted short run and long run effects.

\section{Results}

In this section we report our main results on the injury effects of import competition at competing domestic establishments. We estimate equations 1 and 2 to identify the effects using our two measures, and estimate each equation for intervals $d$ of increasing length to examine how the effects on injuries evolve over time. We first address our main hypothesis - that Chinese import competition increased injury rates for competing US manufacturing workers at smaller establishments in the market. We then discuss our results across intervals of increasing length and how the estimated injury effects evolve over time. 


\subsection{Injury Effects of Import Competition at Competing Plants}

Equation 1 identifies the effect of a supply-driven increase in Chinese imports in an industry on the change in injury rates across establishments. We specify the model in log differences over one to six years and estimate each separately using 2SLS, where Chinese import growth in the US and its interaction with establishment employment are both instrumented with the corresponding import growth in other high-income countries and its interaction with employment. The IVs for one-year intervals fail a weak instrument test in the first stage, suggesting Chinese import growth in other high-income countries is insufficiently correlated with that in the US to identify the model using such a short interval. The measures are significantly correlated for all longer intervals.

The second stage results for equation 1 are shown in Table 3. For all intervals, we find that Chinese import shocks in an industry increased injury rates at the smallest competing US establishments $\left(\beta_{1}>0\right)$ and the effects were decreasing in size $\left(\beta_{2}<0\right)$. Under the identifying assumptions for our 2SLS strategy, these effects are the result of Chinese productivity gains and falling trade costs. The estimates for both coefficients of interest are statistically significant for all specifications save that for one-year changes.

For each interval, we identify the heterogeneous effects across the distribution of plants by estimating the linear combination $\beta_{1}+\beta_{2} \times \ln (L)$ for the smallest decile, median, and largest decile of employment size. We then use the mean log-growth in imports for each interval (about 0.25 per year) to scale up the estimates for interpretation. The estimated effects of the mean growth in imports for each specification are shown in Table 3.

We first evaluate the relationship between imports and injuries using the results of the specification for five-year changes, consistent with related work (e.g. Bloom et al., 2012; Amiti 
and Davis, 2011; Bernard et al., 2006a, 2006b), and discuss the differences in the magnitudes of the coefficients across intervals in detail below. Shown in column 5 of Table 3, we estimate that the mean growth in Chinese imports over a five-year interval in our sample - about $128 \%$ increased injury rate growth over that period by 13 percentage points at the smallest decile of establishments $(\mathrm{p}<0.01)$ and 10 percentage points at the median $(\mathrm{p}<0.05)$. Figure 2 presents our estimates for the distribution of marginal effects across establishment size for this specification, along with the distribution of employment in the sample. The results show that Chinese import growth attributable to falling trade costs and productivity gains had a significant and adverse effect on worker health in the competing industry at all but the largest plants, those with greater than 250 employees.

In our second model, we estimate equation 2 to identify the effects of the US granting China permanent tariff reductions on injury rates. We use the difference-in-difference estimator for identification, comparing within-establishment changes in injury rates in an industry over the $d$-years that followed PNTR in 2001 with the changes over the $d$-years preceding it based on the magnitude of the NTR gap. We estimate the model separately for intervals $d=[1,5]$. Each sample consists of two sets of changes, those from 2001-d to 2001 and those from 2001 to $2001+d$. The import shock in the equation is captured by the interaction of the NTR gap for the industry and an indicator for the post-PNTR period (observations with base year $t=2001$ ). The coefficient identifies the difference in injury rate changes before and after PNTR that are explained by the NTR gap. As before, we interact the measure of import competition with employment size to allow for heterogeneous effects across establishments in an industry.

The results for each specification of equation 2 are presented in Table 4 . We find the liberalization significantly affected injury rates at US manufacturing establishments in industries 
facing a larger permanent tariff reduction. Consistent with the results of the first model, we estimate $\beta_{1}$ to be positive and $\beta_{2}$ to be negative: injury rates at the smallest US manufacturing establishments in were increasing in the industry NTR gap following the policy change in 2001, and the effects were diminishing in establishment size. The coefficient estimates are statistically significant for intervals of three or more years.

The estimated marginal effects for the smallest decile, median, and largest decile of establishments in the sample are scaled up by the mean NTR gap for the sample - about 0.28 for all specifications - and provided in each column of Table 4. Looking again to the estimates of the five-year differences specification shown in column 5, we estimate that the US granting China PNTR in 2001 increased injury rates by 5.8 percentage points at the smallest decile of manufacturing establishments $(\mathrm{p}<0.01)$, weakly increased injuries at the median and weakly decreased injuries at the largest decile.

We find that the permanent tariff reductions granted China in 2001 adversely impacted worker injury and illness outcomes at smaller plants in competing manufacturing industries over the five years following the policy change; at the largest plants, safety may be improving, though the evidence is not statistically significant. These results provide direct evidence of changes in tariff policy affecting worker health at competing domestic establishments, and are, to our knowledge, the first results to do so. Our findings complement ongoing work by Hummels et al. (2014) that looks at the worker injury effects of Danish exports.

\subsection{Short versus Long Run Changes}

Having established the link between import shocks and injury rates over five to six year intervals, we now turn to addressing how these effects evolve over time by comparing the estimates across intervals. We begin by considering the estimates using NTR gap as the measure 
of import competition. The model is identified using a one-time shock - tariffs were only permanently reduced once - and so it provides a relatively clean platform for studying how the effects developed over time. The estimated growth in injuries at the bottom decile across the intervals indicates that the effects of PNTR on injury rates at small establishments are negligible at first but thereafter grow in magnitude over longer intervals following the shock, suggesting that the injury effects of the policy change are increasing and persistent over this time horizon. The trend is congruent with Pierce and Schott (2013), who estimate that the effects of PNTR on cumulative employment growth in US manufacturing over the $d=[1,6]$ years following 2001 are (in percentage points): $-3,-6,-11,-13,-15,-16$. Our estimates for the effects of PNTR on injury rates at the median plant size are positive and follow a similar trend over time, but are not statistically significant. The estimates for the largest plants suggest injury rates may improve in the long run at the most productive establishments as a result of the liberalization, though the results are not statistically significant five years out.

The trend in the estimates from the first model across interval length is similar. The estimated effects of the mean $\log$ growth in Chinese imports $-0.25 \log$ points each year as the intervals are lengthened - are small and statistically insignificant for two to three year intervals and become larger and significant after four to five years and seem to peak there. In this model, however, the measure of import competition is dynamic, which makes it difficult to disentangle lagged responses to earlier shocks from responses to contemporaneous shocks (i.e. significant import growth in an industry in a year was not likely followed by zero growth over the years that followed). Both delayed effects and persistent shocks jointly explain changes in the estimated injury effects across longer intervals, a relative disadvantage of this measure as compared to identification using PNTR. Still, the trends in the estimated injury effects across shorter and 
longer intervals are similar for both models and consistent with outside evidence on the timing of adjustments in other dimensions following a trade shock.

\section{Magnitudes}

We derive back-of-the-envelope estimates for the number injury and illness cases among US manufacturing workers attributable to Chinese import growth over the preceding five years. To derive these, we predict the log growth in injuries at establishments in the sample under both the realized trade conditions and the counterfactual of no import growth over the period We then aggregate the estimates to derive predictions for the log growth in injuries across all US manufacturing workers. ${ }^{28}$ From these and the average log injury rate in the base year, we back out the predicted injury rates in the ending period for US manufacturing workers under both scenarios. We multiply these by manufacturing employment to get the predicted number of injuries in year $t+d$ for each case and compare the two to estimate the number of injuries attributable to Chinese import growth. In calculating these counterfactual estimates, we make the strong assumption that the other parameters of the models are unchanged by the level of the import shock, including the industry and year fixed effects.

The back-of-the-envelope estimates are presented in Table 7. The realized growth in Chinese imports, relative the counterfactual of no change, increased injury and illness incidence by 0.51 cases annually per 100 workers in our sample of establishments and accounted for $7.4 \%$ of all cases. When applied to total US manufacturing employment, these estimates attribute about 75,000 injuries and illnesses each year to the import shock. Plants with less than 40 employees lie outside our sample, however. As a lower bound, we consider the case that injury

\footnotetext{
${ }^{28}$ In aggregating, we first create an industry average using establishment-level effects and weighting each by plant employment, reported in the ODI data, and then we aggregate across industries and weight each by the manufacturing employment shares reported by the BLS.
} 
rates at these small, out-of-sample establishments - which employ about $17 \%$ of manufacturing workers - are unaffected by the shock. In this event, we estimate the import shock accounted for just over 62,000 cases annually. On the other hand, the number may be greater than 75,000 if injury rates increase by more than the mean at these small plants, consistent with our theory and empirical finding that the effects are greatest at smaller establishments in the sample. For the plants in our sample with less than 50 workers, we estimate the realized import growth accounted for 1.06 injuries per 100 workers, or $11.6 \%$ of observed cases. Extending these estimated effects to the 2.5 million workers at out-of-sample establishments would imply 26,500 injuries at those plants and therefore 90,000 in total across all US manufacturing establishments. In summary, we estimate that Chinese import growth accounted for 62,000-90,000 injuries and illnesses among US manufacturing workers each year.

We estimate the welfare costs of these effects using injury cost estimates from the value of statistical life literature. Most studies regress a Mincer wage equation on nonfatal injury risk, along with other individual and occupational characteristics, to solve for the compensating wage differential workers demand for exposure to a level of risks of nonfatal injury or illness risk at work. Together, the risk and the accompanying wage premium produce an estimate for the implied cost of a nonfatal injury or illness to workers. Estimates for the value of nonfatal occupational injury and illness vary considerably, but generally range from $\$ 35,000$ to $\$ 100,000$ in 2004 USD (Viscusi, 1993; Hersch, 1998; Leeth and Ruser. 2003). Based on these values, we estimate the increased morbidity resulting from Chinese import growth cost US manufacturing workers between $\$ 2.2$ billion and $\$ 9$ billion annually, or between $.4 \%$ and $1.6 \%$ of yearly wages. This is in addition to the direct and indirect costs to firms and the government. 
The heterogeneity we estimate in the injury effects of import competition shows that these costs are not borne equally by all workers but are instead focused at the smallest establishments in the sample. To examine this, we grouped establishments into employment size categories and replicated the back-of-the-envelope exercise described above to estimate the injury effects of the shock for each group, where establishments are again weighted by employment (within their size category). Figure 3 shows the predicted injury rates for 2007 under both trade environments across establishments with employment of less than 50, 50-99, 100-249, 250-499, 500-999, and 1000 or more. The predicted effects of Chinese import growth are greatest at the smallest plants in the sample and diminishing in size to negligible effects at plants with 1000 or more employees. The estimates imply an additional 1.02 injuries per 100 workers at plants with less than 50 employees, while the increase was only 0.04 for workers at the largest group of establishments.

\section{Robustness}

Alternative explanations need to account for why changes in reported injury rates are heterogeneous across industries and higher in industries with the greatest increase in Chinese imports and greater permanent tariff reductions and also why those effects are heterogeneous across establishments in an industry. One concern is bias in the dependent variable due to misreporting, where our estimated effects of import competition on the injury data are instead explained by its effects on worker reporting behavior and not actual changes in the number of injuries that occur. Channels that affect firm and worker safety decisions and realized on-the-job injuries and illnesses also generally affect firm and worker incentives with regards to reporting and classifying incidents that occur. Changes in workers reporting behavior in response to import competition would affect our estimates of $\beta_{1}$, as well as $\beta_{2}$ if the effects on misreporting 
are heterogeneous across establishments, independent of changes in the true rate of injuries and illnesses that occur. Changes in reporting behavior only are not costless - in part, they affect the firm's medical and workers' compensation costs - but they do not imply the same costs to worker welfare if the realized injury rate is unchanged. Therefore, it is important to distinguish whether our results are driven by actual changes in injuries or changes in reporting only.

As a robustness exercise, we estimate the two models on the rate of fatal and serious nonfatal injuries and illnesses - those that required days away from work or job restrictions only. Our assumption is that these injuries are less susceptible to strategic reporting by workers and therefore the results are more robust to this potential bias in the left-hand variable of the equations.

The results for the two measures are shown in Tables 5 and 6. Across both models and the interval durations estimated, the results are consistent with those of our main specification: import competition worsened injury rates in competing industries at the smallest plants and the effects were diminishing in plant size.

\section{Conclusion}

We find empirical evidence that the growth in Chinese imports in the US in the late 1990s and early 2000s significantly increased worker injury and illness rates in the competing industries in the short to medium run. We find that one significant contributor to these effects was the change in US trade policy in 2001, when import tariffs on Chinese goods were permanently reduced. The heterogeneous within-industry effects were greatest for small establishments and diminishing in establishment size. We estimate that the mean five-year growth in Chinese imports (128\%) increased injury and illness rates by $10 \%$ on average at plants in the competing industry over the same interval, and about $13 \%$ at the smallest decile of plants. 
Our theoretical model predicts that firms respond to greater shutdown risk by allocating resources towards productivity at the expense of safety. Based on the theory, we hypothesize that import competition will deteriorate worker health outcomes in the short run at marginal firms at risk of being pushed from the market during the transition to the new open economy equilibrium. This mechanism - substituting resources away from safety and into productivity allows firms to prolong their life in the market and slow down the adjustment process following a trade liberalization, but does so at the cost of worker welfare.

Our empirical results imply that worker health is an important channel for welfare effects of trade, even for a developed economy with strong institutions, and therefore should inform trade policy. Further, they suggest that occupational safety and health supervision and regulatory policies targeted towards industries affected by import competition, and the marginal firms within them in particular, could help ameliorate the adverse effects that arise there and may facilitate the adjustment process by leading less productive firms to exit the market sooner in the transition. 


\section{References}

Akerlof, George A. 1982. Labor Contracts as a Partial Gift Exchange. Quarterly Journal of Economics 97(4): 543-69.

---. 1984. Gift Exchange and Efficiency-Wage Theory: Four Views. American Economic Review (74)2, Papers and Proceedings of the Ninety-Sixth Annual Meeting of the American Economic Association: 79-83.

Akerlof, George A. and Janet L. Yellen, eds. 1986. Efficiency Wage Models of the Labor Market. New York: Cambridge University Press.

---. 1988. Fairness and Unemployment. American Economic Review 78(2): 44-9.

---. 1990. The Fair Wage-Effort Hypothesis and Unemployment. Quarterly Journal of Economics 105(2): 255-83.

Amiti, Mary, and Donald R. Davis. 2012. Trade, firms, and wages: Theory and evidence. The Review of Economic Studies 79(1): 1-36.

Arkolakis, C., Costinot A. and Rordiguez-Clare A. 2012. New Trade Models, Same Old Gains? American Economic Review, 2012, 102(1), 94-130

Autor, David H., David Dorn, and Gordon H. Hanson. 2013. The China Syndrome: Local Labor Market Effects of Import Competition in the United States. American Economic Review 103(6): 2121-68.

Barattieri, Alessandro, Susanto Basu, and Peter Gottschalk. 2014. Some Evidence on the Importance of Sticky Wages. American Economic Journal: Macroeconomics 6: 70-101.

Bernard, Andrew B, J Bradford Jensen and Peter K. Schott. 2009. Products and Productivity. Scandinavian Journal of Economics 111(4): 681-709.

---. 2006a. Survival of the Best Fit: Exposure to Low-Wage Countries and the (Uneven) Growth of US Manufacturing Plants. Journal of International Economics 68(1): 219-237.

---. 2006b. Trade Costs, Firms and Productivity. Journal of Monetary Economics 53(5): 917-37.

Bloom, Nicholas, Mirko Draca, and John van Reenen. 2012. Trade Induced Technical Change? The Impact of Chinese Imports on Innovation, IT and Productivity. NBER Working Paper No. 16717

Bloom, Nicholas and John can Reenen. 2007. Measuring and Explaining Management Practices Across Firms. Quarterly Journal of Economics 122(4):1351-1408.

Boone, Jan, Jan C. van Ours, Jean-Philippe Wuellrich, and Josef Zweimuller. 2011. Recessions are Bad for Workplace Safety. Journal of Health Economics 30(4): 764-73.

Boone, Jan and Jan C. van Ours. 2006. Are Recessions Good for Workplace Safety? Journal of Health Economics 25(1): 1069-1093.

Brown, Drusilla K. 2007. Globalization and Employment Conditions Study. World Bank. Social Protections Discussion Paper 708.

Brown, Drusilla K., Alan V. Deardorff, and Robert M. Stern. 2002. Child Labor: Theory, Evidence and Policy. Research Seminar in International Economics Discussion Paper 474. Ann Arbor, University of Michigan.

---. 1996. International Labor Standards and Trade: A Theoretical Analysis, in Jagdish Bhagwati, and Robert Hudec, eds., Fair trade and harmonization: Prerequisites for free trade? Cambridge, MA: MIT Press. 227-80

Campbell III, Carl M. and Kunai S. Kamlani. 1997. The Reasons for Wage Rigidty: Evidence from a Survey of Firms. Quarterly Journal of Economics 112(3): 759-89.

Choi, Don and Alan S. Blinder. 1990. A Shred of Evidence on Theories of Wage Stickiness. Quarterly Journal of Economics 105(4): 1003-1015. 
Davis, Donald R., and James Harrigan. 2011. Good jobs, bad jobs, and trade liberalization. Journal of International Economics 84(1): 26-36.

Demidova, Svetlana. 2008. Productivity Improvements and Falling Trade Costs: Boone or Bane? International Economic Review 49(4): 1437-62.

Demidova, Svetlana and Andrés Rodriguez-Clarez. 2013. The Simple Analytics of the Melitz Model in a Small Open Economy. Journal of International Economics 90(2): 266-72.

Ebenstein, Avraham, Ann Harrison, Margaret McMillan, and Shannon Phillips. Forthcoming. Estimating the Impact of Trade and Offshoring on American Workers Using the Current Population Surveys. Review of Economics and Statistics.

Edmonds, Eric V. and Nina Pavcnik. 2006. International Trade and Child Labor: Cross Country Evidence. Journal of International Economics 68(1): 115-140.

---. 2005. The Effect of Trade Liberalization on Child Labor. Journal of International Economics 65(2): 401-44.

Egger, Hartmut and Udo Kreickemeier. 2009. Firm Heterogeneity and the Labor Market Effects of Trade Liberalization. International Economic Review 50(1): 187-215.

Eslava, Marcela, John Haltiwanger, Adriana Kugler, and Maurice Kugler. 2004. The Effects of Structural Reforms on Productivity and Profitability Enhancing Reallocation: Evidence from Colombia. Journal of Development Economics 75(2): 333-71.

Feenstra, Robert C., John Romalis, and Peter K. Schott. 2002. US Imports, Exports, and Tariff Data, 1989-2001. NBER Working Paper No. w9387.

Fernandes, Ana M. 2007. Trade Policy, Trade Volumes and Plant-Level Productivity in Colombian Manufacturing Industries. Journal of International Economics 71(1): 52-71.

Fischer, Stanley. 1977. Long-term contracts, rational expectations, and the optimal money supply rule. Journal of Political Economy 85(1):191-205.

Handley, Kyle and Nuno Limão. 2013. Policy Uncertainty, Trade and Welfare: Theory and Evidence for China and the US NBER Working Paper No. 19376.

Helpman, Elhanan, Oleg Itskhoki and Stephen Redding. 2010. Inequality and Unemployment in a Global Economy. Econometrica 78(4): 1239-83.

---. 2011. Trade and Labor Market Outcomes. NBER Working Paper No. 16662.

Helpman, Elhanan, Oleg Itskhoki, Marc-Andreas Muendler, and Stephen Redding. 2013. Trade and Inequality: From Theory to Estimation. NBER Working Paper No. 17991.

Hummels, David, Jakob Munch and Chong Xiang. 2014. No Pain, No Gain: The Effects of Globalization on Job Injury and Sickness. Working Paper.

Krugman, Paul. 2008. Trade and Wages, Reconsidered. Brookings Papers on Economic Activity 1: 103-154.

Lazear, Edward P., Kathryn L. Shaw, and Christopher Stanton. 2013. Making Do With Less: Working Harder During Recessions. NBER Working Paper No. 19328.

Leigh, J. Paul. 2011. Economic Burden of Occupational Injury and Illness in the United States. Millbank Quarterly 89(4): 728-772

Liu, Runjuan and Daniel Trefler. 2008. Much Ado About Nothing: American Jobs and the Rise of Service Outsourcing to China and India. NBER Working Paper No. 14061.

Melitz, Marc J. 2003. The Impact of Trade on Intra-Industry Reallocations and Aggregate Productivity. Econometrica 71(6):1695-1725.

Melitz, Marc J. and Redding Stephen. 2014. New Trade Models, New Welfare Implications. American Economic Review, forthcoming 
Muendler, Marc-Andreas. 2004. Trade, Technology, and Production. A Study of Brazilian Manufacturers, 1986-1998. CESifo Working Paper No. 1148.

Pavcnik, Nina. 2002. Trade Liberalization, Exit, and Productivity Improvement: Evidence from Chilean Plants. Review of Economic Studies 69(1): 245-76.

Pierce, Justin R. and Peter K. Schott. 2012. A Concordance Between Ten-Digit US Harmonized System Codes and SIC/NAICS Product Classes and Industries. Journal of Economic and Social Measurement 37(1): 61-96.

---. 2013. The Surprisingly Swift Decline of US Manufacturing Employment. CESifo Working Paper No. 4563.

Probst, Tahira M. and Ty L. Brubaker. 2001. The Effects of Job Insecurity on Employee Safety Outcomes: Cross-Sectional and Longitudinal Explorations. Journal of Occupational Health Psychology 6(2): 139-59.

Revenga, Ana. 1997. Employment and Wage Effects of Trade Liberalization: The Case of Mexican Manufacturing. Journal of Labor Economics 15(S3): S20-S43.

---. 1992. Exporting Jobs? The Impact of Import Competition on Employment and Wages in US Manufacturing. Quarterly Journal of Economics 107(1): 255-284.

Ruhm, Christopher J. 2000. Are Recessions Good for Your Health? Quarterly Journal of Economics 115(2): 617-650.

Shapiro, Carl and Joseph E. Stiglitz. 1984. Equilibrium Unemployment as a Worker Discipline Device. American Economic Review 74(3): 433-44.

Syverson, Chad. 2010. What determines productivity? NBER Working Paper No. 15712.

Verhoogen, Eric A. 2008. Trade, Quality Upgrading, and Wage Inequality in the Mexican Manufacturing Sector. Quarterly Journal of Economics 123(2): 489-530.

Viscusi, Kip. 1983. Risk by Choice: Regulating Health and Safety in the Workplace. Cambridge: Harvard University Press. 
Table 1: Summary Statistics of US Manufacturing Plant-Level Data, 1996-2007

PANEL A: Injury and Employment Data (Full Sample)

\begin{tabular}{|c|c|c|c|}
\hline & Obs. & Mean & Std. Dev. \\
\hline Observations per Plant & 172188 & 3.289 & 2.622 \\
\hline Years Spanned in Data & 172188 & 4.034 & 4.088 \\
\hline Observations/Year Spanned & 172188 & 0.793 & 0.246 \\
\hline Employment & 526931 & 185.64 & 432.36 \\
\hline $10^{\text {th }}$ percentile & & 35 & \\
\hline $25^{\text {th }}$ percentile & & 51 & \\
\hline Median & & 90 & \\
\hline $75^{\text {th }}$ percentile & & 180 & \\
\hline $90^{\text {th }}$ percentile & & 371 & \\
\hline Injury Rate (TCR) & 473014 & 10.38 & 9.50 \\
\hline Injury Rate (TCR) | Non-zero & 420046 & 11.68 & 9.30 \\
\hline Log Injury Rate (TCR) & 420046 & 2.125 & 0.889 \\
\hline 1-year log-change & 192851 & -0.124 & 0.646 \\
\hline 2-year log-change & 152186 & -0.180 & 0.715 \\
\hline 3-year log-change & 137015 & -0.219 & 0.764 \\
\hline 4-year log-change & 117785 & -0.281 & 0.796 \\
\hline 5-year log-change & 93509 & -0.347 & 0.816 \\
\hline 6-year log-change & 72673 & -0.410 & 0.836 \\
\hline Severe Injury Rate (DART) & 474637 & 5.475 & 5.988 \\
\hline Non-Severe Injury Rate & 475549 & 5.071 & 6.350 \\
\hline
\end{tabular}

Notes: Employment imputed from total hours worked as equivalent full-time workers, and excludes observations with imputed plant employment of greater than 25000 . Injury rate statistics exclude observations with imputed injury rates above 60 per 100 workers in a year. Observation intensity is an upper bound as time spanned in data is a lower bound of the spell in eligible pool for selection.

\begin{tabular}{clll}
\hline \hline \multicolumn{2}{l}{ PANEL B: Import Competition Measures } & & \\
\hline & Obs. & Mean & Std. Dev. \\
\hline US Imports from China (000s) & 560784 & 760.0 & 1868.7 \\
1996 Levels (000s) & 59568 & 235.3 & 512.3 \\
2007 Levels (000s) & 43965 & 1587.4 & 3151.9 \\
Log US Imports from China & 558746 & 11.06 & 3.02 \\
1-year log-change & 245123 & 0.264 & 0.750 \\
2-year log-change & 199097 & 0.527 & 0.990 \\
3-year log-change & 181189 & 0.803 & 1.111 \\
4-year log-change & 155399 & 1.062 & 1.196 \\
5-year log-change & 123452 & 1.263 & 1.297 \\
6-year log-change & 95514 & 1.558 & 1.406 \\
OTH Imports from China (000s) & 560558 & 471.0 & 978.3 \\
NTR Gap & 164464 & 0.313 & 0.161 \\
\hline
\end{tabular}

Notes: OTH refers to the set of other OECD countries used to instrument for imports in the US, following Autor et al. (2013). The distribution of NTR gap is across plants only as it is time invariant, all others are across plant-years. 
Table 2: Establishment Size Distribution in Sample and Comparison to Population

\begin{tabular}{|c|c|c|c|c|c|}
\hline \multicolumn{6}{|c|}{ ALL ESTABLISHMENTS } \\
\hline \multirow[b]{2}{*}{ Employment Size } & \multicolumn{2}{|c|}{ ODI Sample } & \multicolumn{2}{|c|}{ Total Industry } & \\
\hline & Establishments & Share of Sample & Establishments & Share of Total & \\
\hline All Establishments & 43850 & 1.000 & 353544 & 1.000 & \\
\hline $1-19$ & 1792 & 0.041 & 239391 & 0.677 & \\
\hline $20-49$ & 8216 & 0.187 & 54665 & 0.155 & \\
\hline$\geq 50$ & 33842 & 0.772 & 59489 & 0.168 & \\
\hline \multicolumn{6}{|c|}{ ESTABLISHMENTS WITH AT LEAST 50 EMPLOYEES } \\
\hline & \multicolumn{2}{|c|}{ ODI Sample } & \multicolumn{2}{|c|}{ Total Industry } & Approximate \\
\hline Employment Size & Establishments & Share of Subsample & Establishments & Share of Subtotal & Coverage \\
\hline All Establishments $\geq 50$ & 33842 & 1.000 & 59489 & 1.000 & 0.569 \\
\hline $50-99$ & 13757 & 0.407 & 26859 & 0.452 & 0.512 \\
\hline $100-249$ & 12607 & 0.373 & 21144 & 0.355 & 0.596 \\
\hline $250-499$ & 4640 & 0.137 & 7229 & 0.122 & 0.642 \\
\hline $500-999$ & 1892 & 0.056 & 2921 & 0.049 & 0.648 \\
\hline$\geq 1000$ & 946 & 0.028 & 1336 & 0.022 & 0.708 \\
\hline \multicolumn{6}{|c|}{$\begin{array}{l}\text { Notes: All establishment counts are averaged across 1996-2007. Industry establishment data are from the County Business } \\
\text { Patterns data and are the sum across all manufacturing industries (SIC4s 2xxx-3xxx for 1996-1997, and NAICS6's 31xxxx- } \\
\text { 33xxxx for 1998-2007). } \\
\text { ODI establishments are grouped by the fulltime employee-equivalent of hours worked and not number of employees, but the } \\
\text { differences across the two employment measures are negligible on aggregate and do not vary considerably across the } \\
\text { distribution of firm sizes (per US Census estimates, the average production worker's hours worked as a share of the fulltime } \\
\text { equivalent was } 1.01 \text { for the smallest firm size class above and 0.99 for the largest). }\end{array}$} \\
\hline
\end{tabular}


Table 3: Injury Effects of Realized Chinese Import Growth (Second Stage IV Results)

Dependent Variable: Log Growth in Injury Rates at Firm $\left(\Delta \ln (T C R)^{t: t+d}\right)$
Import Competition Measure: Log Growth in Chinese Imports in Industry $\left(\Delta \ln \left(M_{u c}\right)^{t: t+d}\right)$

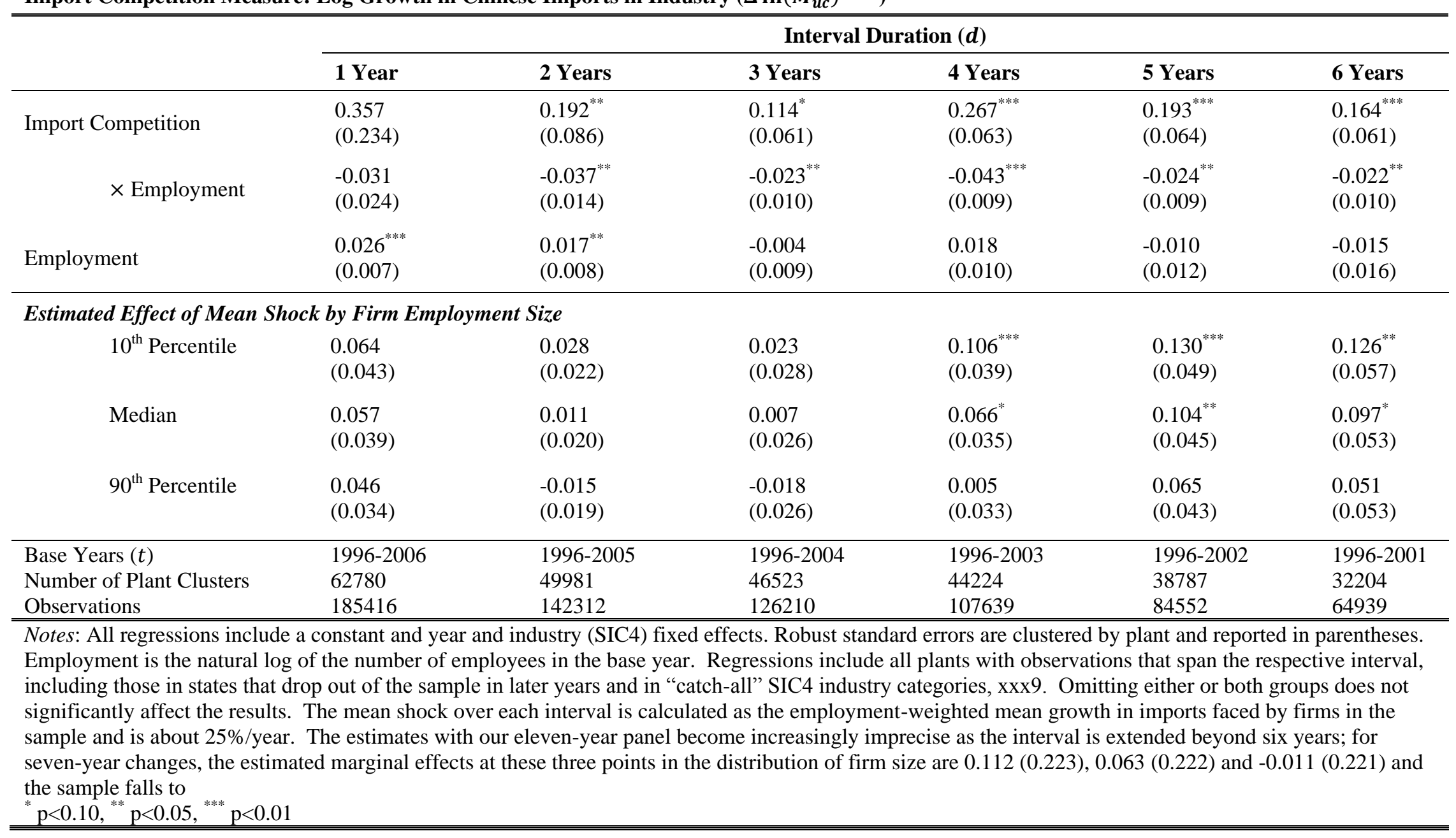


Table 4: Injury Effects of Permanent Import Tariff Reductions Granted China in 2001

\begin{tabular}{|c|c|c|c|c|c|}
\hline \multicolumn{6}{|c|}{$\begin{array}{l}\text { Dependent Variable: Log Growth in Injury Rates at Firm }\left(\Delta \ln (T C R)^{t: t+d}\right) \\
\text { Import Competition Measure: Mean Tariff Reduction for Industry's Goods Permanently Granted China in } 2001\left(1(P o s t-N T R)^{t} \times \text { NTR-Gap) }\right.\end{array}$} \\
\hline & \multicolumn{5}{|c|}{ Interval Duration $(d)$} \\
\hline & 1 Year & 2 Years & 3 Years & 4 Years & 5 Years \\
\hline Import Competition & $\begin{array}{l}-0.094 \\
(0.141)\end{array}$ & $\begin{array}{l}0.148 \\
(0.165)\end{array}$ & $\begin{array}{l}0.414^{* *} \\
(0.173)\end{array}$ & $\begin{array}{l}0.634^{* * * *} \\
(0.179)\end{array}$ & $\begin{array}{l}0.705^{* * * *} \\
(0.190)\end{array}$ \\
\hline$\times$ Employment & $\begin{array}{l}0.022 \\
(0.026)\end{array}$ & $\begin{array}{l}-0.017 \\
(0.031)\end{array}$ & $\begin{array}{l}-0.067^{* *} \\
(0.032)\end{array}$ & $\begin{array}{l}-0.116^{* * *} \\
(0.034)\end{array}$ & $\begin{array}{l}-0.122^{* * *} \\
(0.036)\end{array}$ \\
\hline Employment & $\begin{array}{l}0.000 \\
(0.005)\end{array}$ & $\begin{array}{l}-0.007 \\
(0.007)\end{array}$ & $\begin{array}{l}-0.005 \\
(0.007)\end{array}$ & $\begin{array}{l}0.001 \\
(0.007)\end{array}$ & $\begin{array}{l}-0.023^{* * *} \\
(0.008)\end{array}$ \\
\hline \multicolumn{6}{|c|}{ Estimated Effect of Mean Shock by Firm Size } \\
\hline $10^{\text {th }}$ Percentile & $\begin{array}{l}-0.003 \\
(0.018)\end{array}$ & $\begin{array}{l}0.022 \\
(0.020)\end{array}$ & $\begin{array}{l}0.045^{* *} \\
(0.022)\end{array}$ & $\begin{array}{l}0.051^{* *} \\
(0.022)\end{array}$ & $\begin{array}{l}0.058^{* * *} \\
(0.022)\end{array}$ \\
\hline $90^{\text {th }}$ Percentile & $\begin{array}{l}0.010 \\
(0.018)\end{array}$ & $\begin{array}{l}0.012 \\
(0.020)\end{array}$ & $\begin{array}{l}0.003 \\
(0.021)\end{array}$ & $\begin{array}{l}-0.025 \\
(0.024)\end{array}$ & $\begin{array}{l}-0.014 \\
(0.024)\end{array}$ \\
\hline $\begin{array}{l}\text { Base Years }(t) \\
\text { Number of Plant Clusters } \\
\text { Observations } \\
\mathrm{R}^{2} \\
\end{array}$ & $\begin{array}{l}2000,2001 \\
21468 \\
31781 \\
0.010 \\
\end{array}$ & $\begin{array}{l}1999,2001 \\
17953 \\
25205 \\
0.017 \\
\end{array}$ & $\begin{array}{l}1998,2001 \\
20601 \\
27194 \\
0.017 \\
\end{array}$ & $\begin{array}{l}1997,2001 \\
20672 \\
26114 \\
0.019 \\
\end{array}$ & $\begin{array}{l}1996,2001 \\
21552 \\
27496 \\
0.018 \\
\end{array}$ \\
\hline \multicolumn{6}{|c|}{$\begin{array}{l}\text { Notes: All regressions include a constant and year and industry (SIC4) fixed effects. Robust standard errors are clustered by plant and reported in } \\
\text { parentheses. Employment is the natural log of the number of employees in the base year. Regressions include all plants with observations that span } \\
\text { the respective interval, including those in states that drop out of the sample in later years and in "catch-all" SIC4 industry categories, xxx9. Omitting } \\
\text { either or both groups does not significantly affect the results. The mean shock is calculated as the employment-weighted mean NTR gap for firms in } \\
\text { each sample and is about } 0.28 \text {. } \\
{ }^{*} \mathrm{p}<0.10,{ }^{* *} \mathrm{p}<0.05{ }^{* * *} \mathrm{p}<0.01\end{array}$} \\
\hline
\end{tabular}


Table 5: Robustness to Misreporting: Severe Injury Effects of Realized Chinese Import Growth (Second Stage IV Results)

Dependent Variable: Log Growth in Severe Injury Rates at Firm $\left(\Delta \ln (D A R T)^{t: t+d}\right)$

Import Competition Measure: Log Growth in Chinese Imports in Industry $\left(\Delta \ln \left(M_{u c}\right)^{t: t+d}\right)$

\begin{tabular}{|c|c|c|c|c|c|c|}
\hline & \multicolumn{6}{|c|}{ Interval Duration $(d)$} \\
\hline & 1 Year & 2 Years & 3 Years & 4 Years & 5 Years & 6 Years \\
\hline Import Competition & $\begin{array}{l}0.249 \\
(0.283)\end{array}$ & $\begin{array}{l}0.104 \\
(0.097)\end{array}$ & $\begin{array}{l}0.047 \\
(0.073)\end{array}$ & $\begin{array}{l}0.170^{* *} \\
(0.070)\end{array}$ & $\begin{array}{l}0.153^{* *} \\
(0.068)\end{array}$ & $\begin{array}{l}0.166^{* *} \\
(0.071)\end{array}$ \\
\hline$\times$ Employment & $\begin{array}{l}-0.008 \\
(0.030)\end{array}$ & $\begin{array}{l}-0.016 \\
(0.017)\end{array}$ & $\begin{array}{l}-0.005 \\
(0.012)\end{array}$ & $\begin{array}{l}-0.027^{* * *} \\
(0.010)\end{array}$ & $\begin{array}{l}-0.024^{* *} \\
(0.010)\end{array}$ & $\begin{array}{l}-0.022^{* *} \\
(0.011)\end{array}$ \\
\hline Employment & $\begin{array}{l}0.033^{* * * *} \\
(0.008)\end{array}$ & $\begin{array}{l}0.004 \\
(0.009)\end{array}$ & $\begin{array}{l}-0.028 \\
(0.010)\end{array}$ & $\begin{array}{l}-0.016 \\
(0.012)\end{array}$ & $\begin{array}{l}-0.029^{* *} \\
(0.014)\end{array}$ & $\begin{array}{l}-0.039 \\
(0.016)\end{array}$ \\
\hline \multicolumn{7}{|c|}{ Estimated Effect of Mean Shock by Firm Employment Size } \\
\hline $10^{\text {th }}$ Percentile & $\begin{array}{l}0.058 \\
(0.050)\end{array}$ & $\begin{array}{l}0.022 \\
(0.025)\end{array}$ & $\begin{array}{l}0.023 \\
(0.035)\end{array}$ & $\begin{array}{l}0.070 \\
(0.045)\end{array}$ & $\begin{array}{l}0.075 \\
(0.051)\end{array}$ & $\begin{array}{l}0.125^{*} \\
(0.066)\end{array}$ \\
\hline Median & $\begin{array}{l}0.056 \\
(0.045)\end{array}$ & $\begin{array}{l}0.014 \\
(0.022)\end{array}$ & $\begin{array}{l}0.019 \\
(0.032)\end{array}$ & $\begin{array}{l}0.044 \\
(0.041)\end{array}$ & $\begin{array}{l}0.048 \\
(0.048)\end{array}$ & $\begin{array}{l}0.095^{*} \\
(0.062)\end{array}$ \\
\hline $90^{\text {th }}$ Percentile & $\begin{array}{l}0.053 \\
(0.039)\end{array}$ & $\begin{array}{l}0.003 \\
(0.023)\end{array}$ & $\begin{array}{l}0.013 \\
(0.032)\end{array}$ & $\begin{array}{l}0.007 \\
(0.040)\end{array}$ & $\begin{array}{l}0.008 \\
(0.047)\end{array}$ & $\begin{array}{l}0.048 \\
(0.063)\end{array}$ \\
\hline Base Years $(t)$ & $1996-2006$ & $1996-2005$ & 1996-2004 & $1996-2003$ & $1996-2002$ & 1996-2001 \\
\hline Number of Plant Clusters & 57339 & 45526 & 41872 & 39733 & 34575 & 28680 \\
\hline Observations & 170419 & 130346 & 113785 & 96890 & 75895 & 58266 \\
\hline \multicolumn{7}{|c|}{$\begin{array}{l}\text { Notes: All regressions include a constant and year and industry (SIC4) fixed effects. Robust standard errors are clustered by plant and reported in parentheses. } \\
\text { Employment is the natural log of the number of employees in the base year. Regressions include all plants with observations that span the respective interval, } \\
\text { including those in states that drop out of the sample in later years and in "catch-all" SIC4 industry categories, xxx9. The mean shock over each interval is } \\
\text { calculated as the employment-weighted mean growth in imports faced by firms in the sample and is about } 25 \% / y e a r . \\
{ }^{*} \mathrm{p}<0.10,{ }^{* *} \mathrm{p}<0.05,{ }^{* * *} \mathrm{p}<0.01\end{array}$} \\
\hline
\end{tabular}


Table 6: Robustness to Misreporting: Severe Injury Effects of Permanent Import Tariff Reductions Granted China in 2001

Dependent Variable: Log Growth in Severe Injury Rates at Firm $\left(\Delta \ln (D A R T)^{t: t+d}\right)$

Import Competition Measure: Mean Tariff Reduction for Industry's Goods Permanently Granted China in $2001\left(1(\text { Post-NTR })^{t} \times\right.$ NTR-Gap)

\begin{tabular}{clllll}
\hline \hline & \multicolumn{5}{c}{ Interval Duration $(\boldsymbol{d})$} \\
\cline { 2 - 6 } & $\mathbf{1}$ Year & 2 Years & 3 Years & 4 Years & 5 Years \\
\hline \multirow{2}{*}{ Import Competition } & 0.048 & $0.355^{*}$ & $1.000^{* * *}$ & $0.903^{* * *}$ & $1.09^{* * * *}$ \\
\cline { 2 - 6 } & $(0.63)$ & $(0.195)$ & $(0.202)$ & $(0.214)$ & $(0.220)$ \\
& -0.002 & -0.055 & $-0.177^{* * *}$ & $-0.160^{* * *}$ & $-0.217^{* * *}$ \\
Employment & $(0.030)$ & $(0.036)$ & $(0.038)$ & $(0.040)$ & $(0.042)$ \\
& 0.000 & $-0.023^{* * *}$ & -0.005 & -0.004 & $-0.022^{* *}$ \\
& $(0.006)$ & $(0.008)$ & $(0.008)$ & $(0.008)$ & $(0.009)$ \\
\hline
\end{tabular}

\section{Estimated Effect of Mean Shock by Firm Size}

$\begin{array}{llllll}10^{\text {th }} \text { Percentile } & 0.012 & 0.039 & 0.088^{* * *} & 0.076^{* * *} & 0.053^{* * *} \\ \text { Median } & (0.021) & (0.024) & (0.025) & (0.026) & (0.025) \\ & 0.011 & 0.026 & 0.044^{* *} & 0.035 & 0.002 \\ 90^{\text {th }} \text { Percentile } & (0.019) & (0.022) & (0.022) & (0.024) & (0.024) \\ & 0.011 & 0.006 & -0.022 & -0.027 & -0.077^{* * *} \\ & (0.021) & (0.025) & (0.026) & (0.029) & (0.029)\end{array}$

\begin{tabular}{|c|c|c|c|c|c|}
\hline Base Years $(t)$ & 1996-2006 & 1996-2005 & 1996-2004 & $1996-2003$ & $1996-2002$ \\
\hline Number of Plant Clusters & 19863 & 16586 & 18490 & 18231 & 19209 \\
\hline Observations & 29308 & 23228 & 24479 & 23159 & 24469 \\
\hline $\mathrm{R}^{2}$ & 0.013 & 0.017 & 0.025 & 0.024 & 0.020 \\
\hline
\end{tabular}

Notes: All regressions include a constant and year and industry (SIC4) fixed effects. Robust standard errors are clustered by plant and reported in parentheses. Employment is the natural $\log$ of the number of employees in the base year. Regressions include all plants with observations that span the respective interval, including those in states that drop out of the sample in later years and in "catch-all" SIC4 industry categories, xxx9. The mean shock is calculated as the employment-weighted mean NTR gap for firms in each sample and is about 0.28.

${ }^{*} \mathrm{p}<0.10,{ }^{* * *} \mathrm{p}<0.05,{ }^{* * *} \mathrm{p}<0.01$ 
Table 7: Predicted Injury Effects for Import Growth Specification Under Alternative Trade Environments

\begin{tabular}{|c|c|c|c|c|c|c|c|c|c|}
\hline \multirow[b]{2}{*}{ Year } & \multirow[b]{2}{*}{$\begin{array}{l}\text { Manufacturing } \\
\text { Emp. (000s) }\end{array}$} & \multirow[b]{2}{*}{$\begin{array}{c}\text { Sample } \\
\text { Injury Rate }\end{array}$} & \multicolumn{2}{|c|}{$\begin{array}{c}\text { Predictions | Realized } \\
\text { Chinese Import Growth }\end{array}$} & \multicolumn{2}{|c|}{$\begin{array}{c}\text { Predictions | No } \\
\text { Chinese Import Growth }\end{array}$} & \multicolumn{2}{|c|}{ Difference in Predictions } & \multirow[b]{2}{*}{$\begin{array}{c}\text { Share Cases Attributable } \\
\text { to Import Growth }(\%)\end{array}$} \\
\hline & & & Injury Rate & No. Injuries & Injury Rate & No. Injuries & Injury Rate & No. Injuries & \\
\hline 2001 & 16641 & 6.74 & 6.51 & 1083329 & 6.07 & 1010109 & 0.43 & 73220 & 6.6 \\
\hline 2002 & 15259 & 7.31 & 7.36 & 1123062 & 6.87 & 1048293 & 0.49 & 74769 & 6.7 \\
\hline 2003 & 14509 & 7.41 & 8.57 & 1243421 & 7.90 & 1146211 & 0.67 & 97210 & 7.8 \\
\hline 2004 & 14315 & 6.21 & 8.62 & 1233953 & 7.96 & 1139474 & 0.66 & 94479 & 7.7 \\
\hline 2005 & 14227 & 5.55 & 6.15 & 874961 & 5.75 & 818053 & 0.40 & 56908 & 6.5 \\
\hline 2006 & 14155 & 5.23 & 5.47 & 774279 & 5.03 & 711997 & 0.45 & 62282 & 8.2 \\
\hline 2007 & 13879 & 5.46 & 5.70 & 791103 & 5.22 & 724484 & 0.48 & 66619 & 8.4 \\
\hline Mean & 14712 & 6.31 & 6.92 & 1017730 & 6.41 & 942660 & 0.51 & 75070 & 7.4 \\
\hline
\end{tabular}

Notes: Injury rates are calculated as the Total Case Rate (TCR), the number of reported injuries and illnesses in a year per 100 equivalent fulltime workers. Estimates are from the specification of equation 1 for five-year intervals. Average rates across years are weighted by yearly manufacturing employment. Injury rates are estimated using a data sample restricted to firms with at least 40 employees, but the estimates here are applied to all manufacturing employment. About $17 \%$ of manufacturing workers over this period are employed at plants of less than 40 workers, which lie outside our sample. The estimates for the number of injuries should therefore be multiplied by 0.83 to obtain the estimated effects for workers at plants covered by our sample only and the number of injuries attributable to Chinese import growth under the assumption that injury rates at out-of-sample plants are unaffected. 
Table 8: Import Competition and Incidence of Health in Local Economy (Second Stage IV Results)

Dependent Variable: Geographic (CZ) Change in Self-Reported Health, 2000-2007

Import Competition Measure: Growth in Competing Imports Faced by Average Worker in Region 2000-2007 (Autor et al. (2013) measure)

\begin{tabular}{|c|c|c|c|c|c|}
\hline & \multirow{2}{*}{$\begin{array}{l}\text { General Health } \\
\text { Share Reporting } \\
\text { Overall Not Good (ppts) }\end{array}$} & \multicolumn{2}{|c|}{ Mental Health } & \multicolumn{2}{|c|}{ Physical Health } \\
\hline & & $\begin{array}{l}\text { Share Reporting } \\
\text { Poor Days (ppts) }\end{array}$ & $\begin{array}{l}\text { Avg Poor } \\
\text { Days/Month }\end{array}$ & $\begin{array}{l}\text { Share Reporting } \\
\text { Poor Days (ppts) }\end{array}$ & $\begin{array}{l}\text { Avg Poor } \\
\text { Days/Month }\end{array}$ \\
\hline Observations & 340 & 340 & 340 & 340 & 340 \\
\hline \multicolumn{6}{|c|}{$\begin{array}{l}\text { Notes: Observations are at the Commuting Zone (CZ)-level. Chinese import growth in the US is instrumented in the first stage by growth in other } \\
\text { OECD countries. All regressions include a constant, census division dummies, and the full set of CZ controls used in Autor et al. (2013): percentage } \\
\text { of population that is college-educated, foreign born, employed in manufacturing, and employed in routine occupations, the percentage of employment } \\
\text { among women, and the average offshorability index of occupations. Robust standard errors are clustered by state and reported in parentheses. First } \\
\text { stage results are available upon request. Observations are at the commuting zone level and are weighted by base-year share of national population. } \\
{ }^{*} \mathrm{p}<0.10,{ }^{* *} \mathrm{p}<0.05,{ }^{* * *} \mathrm{p}<0.01\end{array}$} \\
\hline
\end{tabular}


Figure 1: Distribution of Injury Rates at Manufacturing Establishments in ODI Dataset

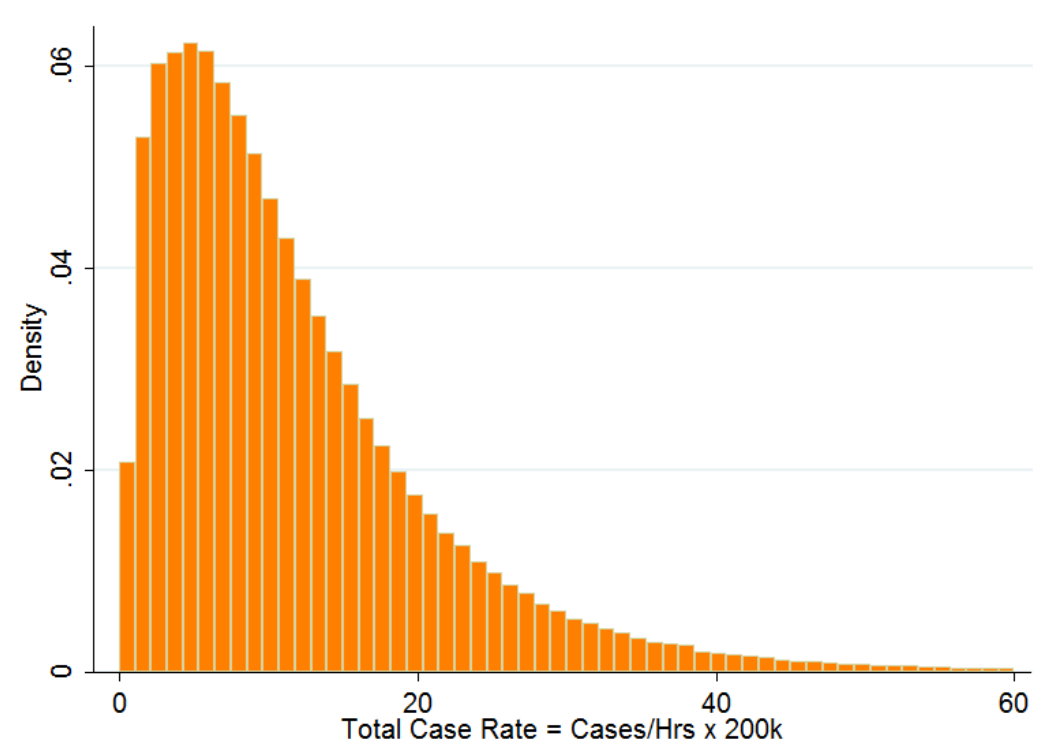

Notes: Injury rates are measured as total cases of injury and illness per 100 full-time workers in a year. Sample is establishment-year observations with $0<\mathrm{TCR}<60$, and omits $11 \%$ of observations with a incidence rate of zero, which are necessarily excluded from our primary estimation in log-differences.

Figure 2: Heterogeneous Health Effects of Import Competition by Establishment Size

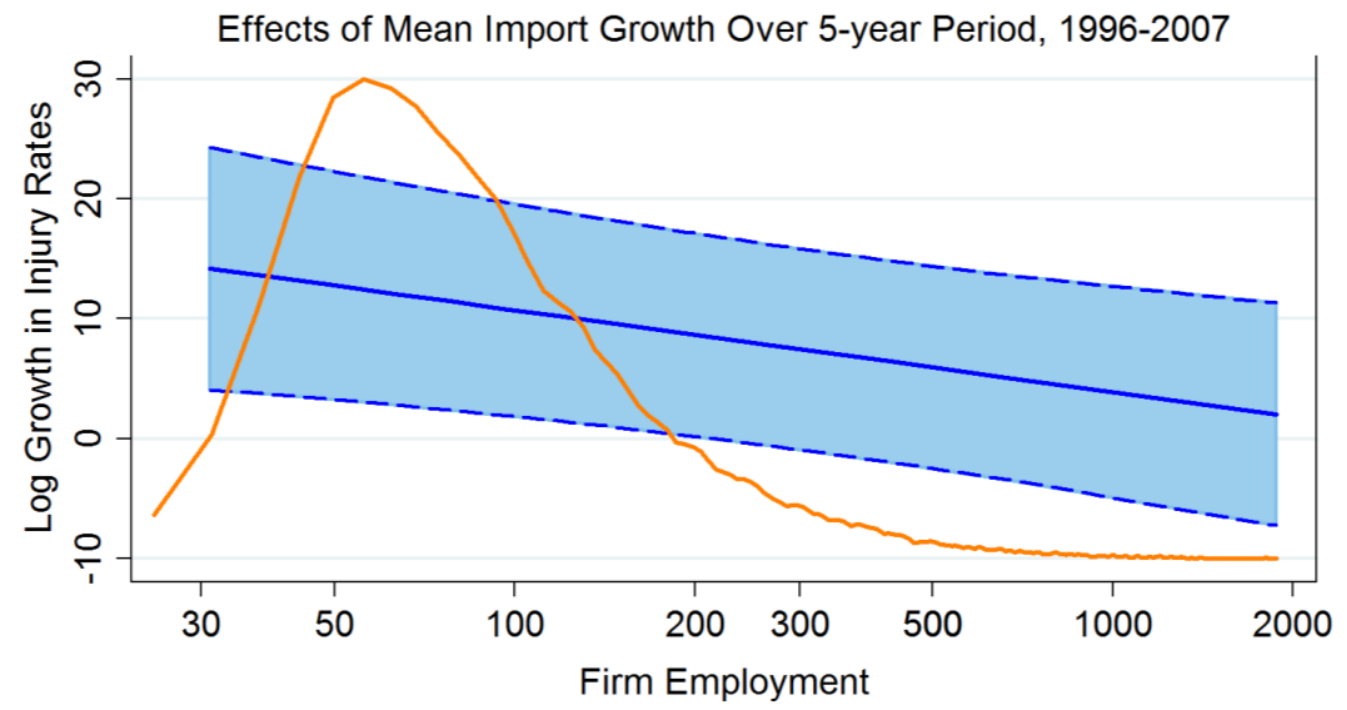

Mean

--- - 95\% Confidence Interval Distribution of Establishment Size in Sample 
Figure 3: Predicted Injury Rates in 2007 under Alternative Trade Environments

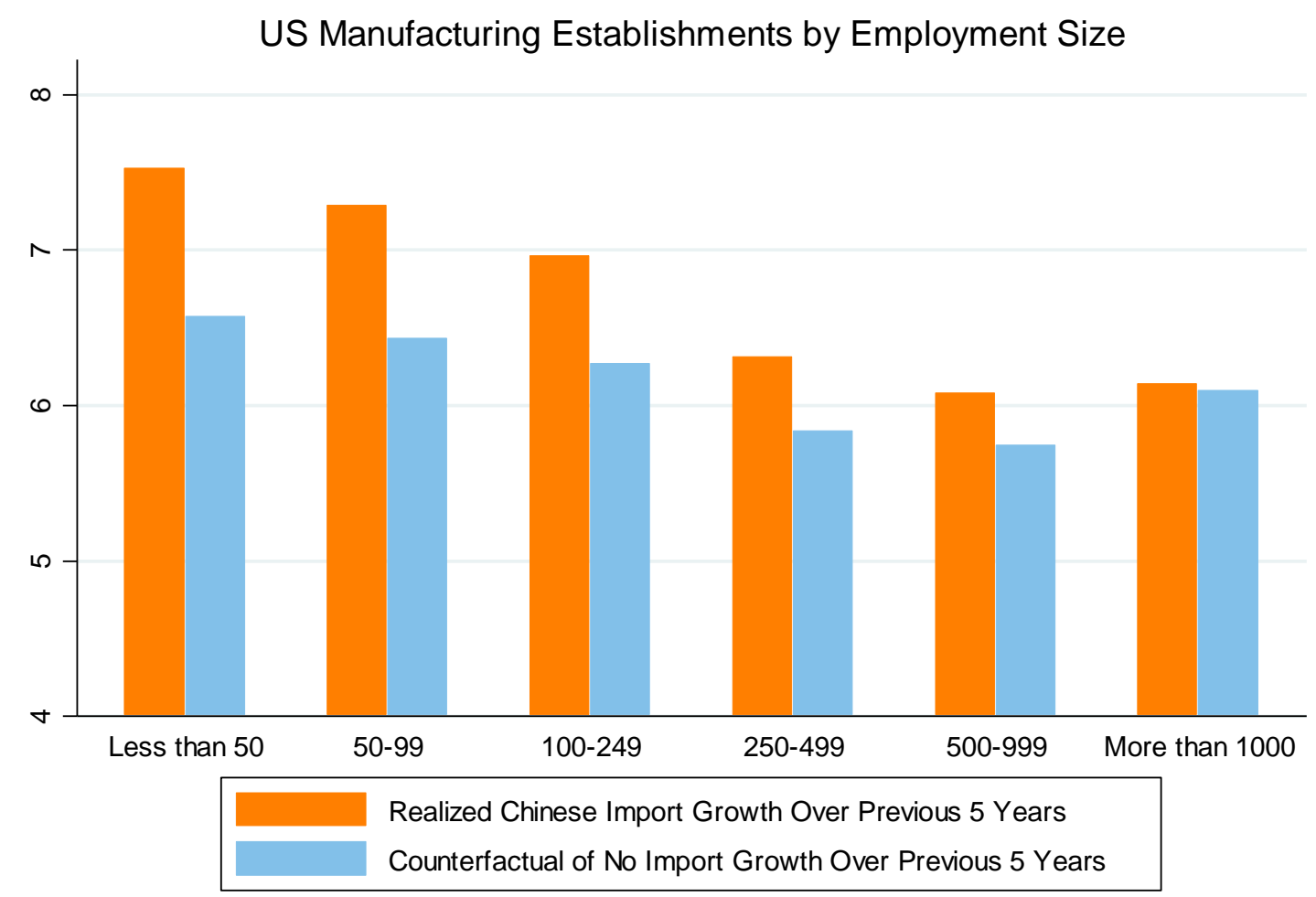




\section{Appendix A: Comparative Statics for General Form Effort and Cost Functions}

In this section we solve for the main theoretical prediction that motivates our empirical hypotheses - that injury rates are inversely related to firm survival - using general forms for the effort and cost functions. The power functions used in the main model yield closed-form solutions which simplify presentation, but the propositions monitoring, effort and, most importantly, injury rates hold under more relaxed assumptions as we demonstrate here.

Demand is as specified in the main model: $p_{M}\left(q_{M}\right)=q_{M}^{-\frac{1}{\sigma}}$. The firm produces output as a function of total employee effort such that there are non-increasing returns to scale: $q=$ $F(e, L)=\varphi(e L)^{\beta}, \beta \leq 1$.

We assume that there are diminishing returns to both monitoring output (effort) and investing in safety, and therefore effort $e$ is increasing and concave in the level of output monitoring $m$ and the probability of a worker being injured $P$ is decreasing and convex in the level of safety investments $s$. The firm is constrained in its resources $T$ such that $s+m=T$. It follows from $s(m)=T-m$ that $P_{m}>0$ and $P_{m m}<0$. Wages are held fixed to simplify the model and normalized to 1 . Lastly, we make the keystone assumption that the expected cost of injuries $C$ is decreasing in the expected probability of the firm shutting down each period $\delta$. Here, let $C$ also encompass any compensating wage premiums that the firm must pay in the current period as a result of the chosen level of risk.

The first-order conditions for the firm decision maker choosing $m$ and $L$ to maximize expected firm profits given the constraints $e(m)$ and $P(m)$ and injury costs $C(\delta)$ are:

$$
\begin{aligned}
& \frac{\partial \pi}{\partial m} \equiv 0: \beta \rho \varphi^{\rho} e^{\beta \rho-1} L^{\beta \rho} e_{m}-P_{m} L C(\delta) \equiv 0 \\
& \frac{\partial \pi}{\partial L} \equiv 0: \beta \rho \varphi^{\rho} e^{\beta \rho} L^{\beta \rho-1}-w-P C(\delta) \equiv 0
\end{aligned}
$$

Defining $L^{*}=L^{*}(\delta)$ and $m^{*}=m^{*}(\delta)$ and implicitly differentiating with respect to $\delta$ yields the following system of equations in matrix form:

$$
\begin{aligned}
& {\left[\begin{array}{cc}
\varphi^{\rho}(\beta \rho)(\beta \rho-1) e^{\beta \rho-2} L^{\beta \rho} e_{m}^{2}+\varphi^{\rho}(\beta \rho) e^{\beta \rho-1} L^{\beta \rho} e_{m m}-P_{m m} C & \varphi^{\rho}(\beta \rho)^{2}(e L)^{\beta \rho-1} e_{m}-P_{m} C \\
\varphi^{\rho}(\beta \rho)^{2}(e L)^{\beta \rho-1} e_{m}-P_{m} C & \varphi^{\rho}(\beta \rho)(\beta \rho-1) e^{\beta \rho} L^{\beta \rho-2}
\end{array}\right]\left[\begin{array}{c}
\frac{\partial m^{*}}{\partial \delta} \\
\frac{\partial L^{*}}{\partial \delta}
\end{array}\right]} \\
& \equiv\left[\begin{array}{c}
P_{m} L c_{\delta} \\
P C_{\delta}
\end{array}\right]
\end{aligned}
$$

Proposition 1a: An increase in the probability of the firm shutting down increases the amount of resources the firm allocates to monitoring output.

Proof: By Cramer's Rule,

$$
\begin{aligned}
& \frac{\partial m^{*}}{\partial \delta} \\
& =\frac{\left|\begin{array}{cc}
P_{m} L C_{\delta} & \varphi^{\rho}(\beta \rho)^{2}(e L)^{\beta \rho-1} e_{m}-P_{m} C \\
P C_{\delta} & \varphi^{\rho}(\beta \rho)(\beta \rho-1) e^{\beta \rho} L^{\beta \rho-2}
\end{array}\right|}{\left|\begin{array}{cc}
\varphi^{\rho}(\beta \rho)(\beta \rho-1) e^{\beta \rho-2} L^{\beta \rho} e_{m}^{2}+\varphi^{\rho}(\beta \rho) e^{\beta \rho-1} L^{\beta \rho} e_{m m}-P_{m m} C & \varphi^{\rho}(\beta \rho)^{2}(e L)^{\beta \rho-1} e_{m}-P_{m} C \\
\varphi^{\rho}(\beta \rho)^{2}(e L)^{\beta \rho-1} e_{m}-P_{m} C & \varphi^{\rho}(\beta \rho)(\beta \rho-1) e^{\beta \rho} L^{\beta \rho-2}
\end{array}\right|}
\end{aligned}
$$


We assume that the second-order conditions for a unique maximum are satisfied and therefore $\operatorname{sign}\left(\frac{\partial m^{*}}{\partial \delta}\right)=\operatorname{sign}\left(P_{m} L c_{\delta} \varphi^{\rho}(\beta \rho)(\beta \rho-1) e^{\beta \rho} L^{\beta \rho-2}-P C_{\delta} \varphi^{\rho}(\beta \rho)^{2}(e L)^{\beta \rho-1} e_{m}+P C_{\delta} P_{m} C\right)$ For $C_{\delta}<0$,

$$
\operatorname{sign}\left(\frac{\partial m^{*}}{\partial \delta}\right)=-\operatorname{sign}\left(P_{m} \varphi^{\rho}(\beta \rho)(\beta \rho-1) e^{\beta \rho} L^{\beta \rho-1}-P \varphi^{\rho}(\beta \rho)^{2}(e L)^{\beta \rho-1} e_{m}+P P_{m} C\right) .
$$

Substitute for $P C$ in the last term using the second FOC and we have

Or,

$$
\begin{aligned}
\operatorname{sign}\left(\frac{\partial m^{*}}{\partial \delta}\right)= & -\operatorname{sign}\left(P_{m} \varphi^{\rho}(\beta \rho)(\beta \rho-1) e^{\beta \rho} L^{\beta \rho-1}-P \varphi^{\rho}(\beta \rho)^{2}(e L)^{\beta \rho-1} e_{m}\right. \\
& \left.+P_{m} \varphi^{\rho}(\beta \rho) e^{\beta \rho} L^{\beta \rho-1}-P_{m} w\right) .
\end{aligned}
$$

$$
\begin{aligned}
\operatorname{sign}\left(\frac{\partial m^{*}}{\partial \delta}\right)= & -\operatorname{sign}\left[\varphi^{\rho}(\beta \rho)^{2}(e L)^{\beta \rho-1}\left[P_{m} e-P e_{m}\right]-P_{m} w\right] \\
& =\operatorname{sign}\left[P_{m} w-\varphi^{\rho}(\beta \rho)^{2}(e L)^{\beta \rho-1}\left[P_{m} e-P e_{m}\right]\right]
\end{aligned}
$$

Setting the FOCs equal yields $\beta \rho \varphi^{\rho} e^{\beta \rho} L^{\beta \rho} \equiv L(w+P C) \equiv \frac{e}{e_{m}} P_{m} L C$, and therefore $\left(P_{m} e-P C\right) \equiv \frac{w e_{m}}{C}$. So substituting for $\left(P_{m} e-P C\right)$ and factoring out $\frac{w}{C}$, we have

$$
\operatorname{sign}\left(\frac{\partial m^{*}}{\partial \delta}\right)=\operatorname{sign}\left[P_{m} C-\varphi^{\rho}(\beta \rho)^{2}(e L)^{\beta \rho-1} e_{m}\right] \text {. }
$$

From the first FOC, $P_{m} C \equiv \beta \rho \varphi^{\rho}(e L)^{\beta \rho-1} e_{m}$ so therefore

$$
\operatorname{sign}\left(\frac{\partial m^{*}}{\partial \delta}\right)=\operatorname{sign}(1-\beta \rho)>0 \text {. }
$$

Proposition 1b: An increase in the probability of the firm shutting down increases worker effort.

Proof: By assumption, $e^{*}=e\left(m^{*}\right)$ such that $e_{m}>0$ and therefore

$$
\operatorname{sign}\left(\frac{\partial e\left(m^{*}(\delta)\right)}{\partial \delta}\right)=\operatorname{sign}\left(\left(\frac{\partial e}{\partial m}\right)\left(\frac{\partial m^{*}}{\partial \delta}\right)\right)=\operatorname{sign}\left(\frac{\partial m^{*}}{\partial \delta}\right)>0 \text {. }
$$

Proposition 2: An increase in the probability of the firm shutting down increases the likelihood of worker injury at the firm.

Proof: By assumption, $P^{*}=P\left(m^{*}\right)$ such that $P_{m}>0$. Therefore

$$
\operatorname{sign}\left(\frac{\partial P\left(m^{*}(\delta)\right)}{\partial \delta}\right)=\operatorname{sign}\left(\left(\frac{\partial P}{\partial m}\right)\left(\frac{\partial m^{*}}{\partial \delta}\right)\right)=\operatorname{sign}\left(\frac{\partial m^{*}}{\partial \delta}\right)>0 \text {. }
$$




\section{Appendix B: Theoretical Model with Hedonic Wage Specification}

In this section we present an alternative wage specification for our theoretical model that incorporates compensating wage differentials for injury risk. We show that the main theoretical predictions are similar.

We make the alternative specification that worker effort depends on the monitoring level only, $e(m)=m^{\beta}$ and not the wage, where $0<\beta<1$.

As a consequence of their job, workers at the firm face a risk of work-related injury or illness each period. Suppose that workers are averse to injuries that their value for employment if unhurt is $w$ and their value for employment if hurt is $w-\lambda$, where $\lambda>0$. A risk neutral worker therefore values a job at firm $i$ that entails the probability of injury $P_{i}$ at $w-\lambda P_{i}$. Workers have an outside option of employment in a riskless sector that pays $w_{R}$. Firms must pay workers such that they are at least indifferent between working at the firm and in the riskless sector, or $w_{i}-\lambda P_{i} \geq w_{R}$. This binds in equilibrium, as firms have no incentive to pay more than is necessary for workers to accept the job, so that a worker facing injury risk $P_{i}$ will earn the wage $w_{i}=w_{R}+\lambda P_{i}$.

Injury costs and the probability of injury are as defined in the model, so therefore the firms expected total lifetime costs of injuries in a period is still given by $C L=m^{\gamma} \frac{c}{(\delta+r) d} L$.

The firm's total labor costs depend on the compensating wage differentials and are given by: $w\left(P_{i}\right) L=\left(w_{R}+\lambda m^{\gamma}\right) L$.

Production and demand are also as specified in the model. The competitive good is chosen as the numeraire. It is produced with constant returns to scale and no risk to workers such that its price is $w_{R}$, henceforth normalized to one. The firm's profit function is therefore

which it maximizes subject to the constraint that $m \in[0,1]$.

$$
\max _{m, L} \pi=\varphi^{\rho}\left(m^{\beta} L\right)^{\rho}-w_{R} L-m^{\gamma}\left[\frac{c}{(\delta+r) d}+\lambda\right] L .
$$

The solutions to the firms problem are given by:

$$
\begin{aligned}
& m^{*}=\left[\left(\frac{\beta}{\gamma-\beta}\right)\left(\frac{d(\delta+r)}{c+\lambda d(\delta+r)}\right)\right]^{\frac{1}{\gamma}}, e\left(m^{*}\right)=\left[\left(\frac{\beta}{\gamma-\beta}\right)\left(\frac{d(\delta+r)}{c+\lambda d(\delta+r)}\right)\right]^{\frac{\beta}{\gamma}}, \\
& P\left(m^{*}\right)=\left(\frac{\beta}{\gamma-\beta}\right)\left(\frac{d(\delta+r)}{c+\lambda d(\delta+r)}\right), \text { and } L^{*}=\left[\rho \varphi^{\rho}\left(\frac{\beta}{\gamma-\beta}\right)^{\frac{\beta \rho}{\gamma}}\left(\frac{\gamma-\beta}{\gamma}\right)\left(\frac{d(\delta+r)}{c+\lambda d(\delta+r)}\right)^{\frac{\beta \rho}{\gamma}}\right]^{\frac{1}{1-\rho}}
\end{aligned}
$$

and the proofs for Propositions 1a, 1b, and 2 are, respectively:

$$
\begin{aligned}
& \frac{\partial m^{*}}{\partial \delta}=\left(\frac{c}{\gamma(\delta+r)(c+\lambda d(\delta+r))}\right)\left[\left(\frac{\beta}{\gamma-\beta}\right)\left(\frac{d(\delta+r)}{c+\lambda d(\delta+r)}\right)\right]^{\frac{1}{\gamma}}=\left(\frac{c}{\gamma(\delta+r)(c+\lambda d(\delta+r))}\right) m^{*}>0 . \\
& \frac{\partial e\left(m^{*}\right)}{\partial \delta}=\beta\left(\frac{c}{\gamma(\delta+r)(c+\lambda d(\delta+r))}\right)\left[\left(\frac{\beta}{\gamma-\beta}\right)\left(\frac{d(\delta+r)}{c+\lambda d(\delta+r)}\right)\right]^{\frac{\beta}{\gamma}}=\beta\left(\frac{c}{\gamma(\delta+r)(c+\lambda d(\delta+r))}\right) e\left(m^{*}\right)>0 . \\
& \frac{\partial P\left(m^{*}\right)}{\partial \delta}=\left(\frac{\beta}{\gamma-\beta}\right)\left(\frac{c d}{[c+\lambda d(\delta+r)]^{2}}\right)=\left(\frac{c}{(\delta+r)(c+\lambda d(\delta+r))}\right) P\left(m^{*}\right)>0 .
\end{aligned}
$$

